Article

\title{
Dynamic TMT-Based Quantitative Proteomics Analysis of Critical Initiation Process of Totipotency during Cotton Somatic Embryogenesis Transdifferentiation
}

\author{
Haixia Guo ${ }^{\dagger}$, Huihui Guo ${ }^{\dagger}$, Li Zhang, Yijie Fan, Yupeng Fan, Zhengmin Tang and \\ Fanchang Zeng * (D)
}

State Key Laboratory of Crop Biology, College of Agronomy, Shandong Agricultural University, Tai'an 271018, China; diya_haixiaguo@163.com (H.G.); hhguo@sdau.edu.cn (H.G.); 15610418001@163.com (L.Z.); yjfan@sdau.edu.cn (Y.F.); fanyupeng@chnu.edu.cn (Y.F.); 17861500710@163.com (Z.T.)

* Correspondence: fczeng@sdau.edu.cn; Tel.: +86-538-824-1828

+ These authors contributed equally to this work.

Received: 21 February 2019; Accepted: 2 April 2019; Published: 4 April 2019

\begin{abstract}
The somatic embryogenesis (SE) process of plants, as one of the typical responses to abiotic stresses with hormone, occurs through the dynamic expression of different proteins that constitute a complex regulatory network in biological activities and promotes plant totipotency. Plant SE includes two critical stages: primary embryogenic calli redifferentiation and somatic embryos development initiation, which leads to totipotency. The isobaric labels tandem mass tags (TMT) large-scale and quantitative proteomics technique was used to identify the dynamic protein expression changes in nonembryogenic calli (NEC), primary embryogenic calli (PEC) and globular embryos (GEs) of cotton. A total of 9369 proteins (6730 quantified) were identified; 805, 295 and 1242 differentially accumulated proteins (DAPs) were identified in PEC versus NEC, GEs versus PEC and GEs versus NEC, respectively. Eight hundred and five differentially abundant proteins were identified, 309 of which were upregulated and 496 down regulated in PEC compared with NEC. Of the 295 DAPs identified between GEs and PEC, 174 and 121 proteins were up- and down regulated, respectively. Of 1242 differentially abundant proteins, 584 and 658 proteins were up- and down regulated, respectively, in GEs versus NEC. We have also complemented the authenticity and accuracy of the proteomic analysis. Systematic analysis indicated that peroxidase, photosynthesis, environment stresses response processes, nitrogen metabolism, phytohormone response/signal transduction, transcription/posttranscription and modification were involved in somatic embryogenesis. The results generated in this study demonstrate a proteomic molecular basis and provide a valuable foundation for further investigation of the roles of DAPs in the process of SE transdifferentiation during cotton totipotency.
\end{abstract}

Keywords: cotton; somatic embryogenesis; transdifferentiation; quantitative proteomics; regulation and metabolism; molecular basis; concerted network

\section{Introduction}

Somatic embryogenesis (SE) is a notable illustration of cell totipotency as one of the typical responses to abiotic stresses with hormone, which processes the developmental reprogramming of somatic cells toward the embryogenesis pathway. Cotton (Gossypium hirsutum L.), as the foremost natural fiber source [1] and one of the most important economic crops worldwide, has a global socioeconomic impact worth approximately $\$ 56$ billion [2]. However, plant regeneration in SE is 
still a limiting method for transgenic development in cotton [1,3]. Somatic embryogenesis represents a unique phenomenon in the plant kingdom [4]. This developmental pathway is one of the most striking examples of plant cell developmental plasticity [5,6]. It includes a series of characteristic events, including somatic dedifferentiation, cell division activation, metabolism alterations and gene expression pattern reprogramming [4]. During SE, the development of somatic cells is reprogrammed to the embryogenic pathway, and SE forms the basis of cellular totipotency in higher plants [7]. Each transformed cell has the potential to produce a plant from the callus [8]. Somatic embryogenesis and subsequent plant regeneration have been reported in most major crop varieties [9]. Soybeans and cotton have proven to be the most difficult to regenerate [10].

In cotton, only a few percent of somatic embryos are able to mature and regenerate into plantlets. Most embryos develop abnormally, redifferentiate in to calli, or become necrotic and die [11]. Sakhanokho and Rajasekaran [12] obtained a variety of factors affecting cotton during in vitro regeneration, including plant growth regulators, explants, compositions of media and environmental conditions. The transition of somatic cells into embryogenic cells is the most intriguing and the least understood part of somatic embryogenesis [13-15]. Now, it is generally accepted that stress and hormones play a crucial role in collectively inducing cell dedifferentiation and initiation of the embryogenic program in plants with responsive genotypes [16-18].

Since the first observations of somatic embryo formation in suspension cultures of carrot cells by Stewards [7] and Reinert [19], the potential for SE has been demonstrated to be characteristic of extensive tissue culture systems from both dicotyledonous and monocotyledonous plants $[20,21]$. Considerable efforts have been expended in identifying the various factors that control SE [22,23]. An important gene that marks embryonic cells is the transcription factor gene WUSCHEL (WUS) [24]. Using a genetic gain-of-function screening approach, Zuo et al. [25] found that overexpression of WUS in roots, leaf petioles, stems, or leaves of Arabidopsis can induce the formation of somatic embryos. These results indicate that WUS participates in the promotion and/or maintenance of totipotent embryogenic stem cells. However, the wus mutants are still able to produce somatic embryos, suggesting that multiple alternative pathways can lead to the expression of totipotent potential. WUS is the only transcription factor that has been found to be involved in regulating meristematic stem cells (pluripotent) and embryogenic stem cells (totipotent) [15]. In addition, when auxin biosynthesis rates were manipulated in Arabidopsis embryos, polar auxin transport activity apparently buffered the normal distribution of auxin, suggesting a compensatory mechanism for buffering auxin gradients in the embryo, with PIN1 and PIN4 being the most important genes [26]. The results by Su [27] suggested that the establishment of auxin gradients and the polar distribution of PIN1 are critical for the regulation of WUS expression during somatic embryogenesis. ERF plays an important role in hormone signal transduction and interconnecting different hormone pathways [28]. Inhibition of gibberellin (GA) biosynthesis increases the fraction of lec1-tnp seedlings displaying the mutant phenotype, suggesting that reduced GA levels enhance maturation processes induced by LEAFY COTYLEDON 1 (LEC1) [29]. The plant hormone abscisic acid (ABA) regulates many important plant developmental processes and induces epigenetic reprogramming against tolerance to different stresses, including drought, salinity, low temperature and some pathogens [30,31]. ABA serves as a critical chemical messenger for stress responses. The roles of several genes in somatic embryogenesis masses (SEM) have been well-characterized, including Arabinogalactan protein 1 (AGP1) [32], Glutathione-S-transferase (GST) [33], SOMATIC EMBRYO RELATED FACTOR1 (MtSERF1) [34], BABY BOOM (BBM) [35], Agamous-like 15 (AGL15) [36,37] and SOMATIC EMBRYOGENESIS RECEPTOR-LIKE KINASE (SERK) from Daucus carota, which was the first identified marker gene with a crucial role in SEM [38].

At present, a great number of SE-related genes and transcription factors have been identified at the transcription level. For example, Zeng [39], with the suppression subtractive hybridization (SSH) technique, identified 671 cDNAs in the initial period of SE in cotton. Nonetheless, reports on the identification of cotton SE at high-throughput proteins levels are still insufficient, especially during the initial stage of SE transdifferentiation. Proteomics is a powerful approach aimed at systematic studies 
of protein structure, function, interaction, and dynamics [4]. To further investigate the molecular regulatory mechanisms of somatic embryogenesis, the protein dynamics of NEC, PEC and GE were identified by TMT quantitative proteomics techniques. The highly sensitive proteomic platform based on the isobaric labels tandem mass tags was recently developed as one of the most robust proteomics techniques $[40,41]$. Through identification and annotation of DAPs, we uncovered the key genes/proteins and pathways involved in cotton SE transdifferentiation. The results generated in this study provide a valuable foundation for further investigation of the roles of DAPs in cotton SE.

\section{Results}

\subsection{Somatic Embryogenesis in Cotton}

PEC were formed from NEC after approximately 3 months of culture. The initial development period of GEs from embryogenic callus was the most restrictive step during cotton SEM (Figure 1). To identify proteins related to SE and morphogenesis in cotton, we sampled the critical representative periods of NEC, PEC and GEs for protein preparation and TMT-based quantitative proteomics analyses.

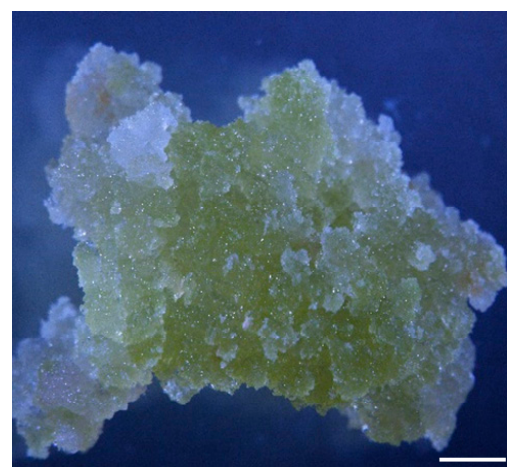

(a)

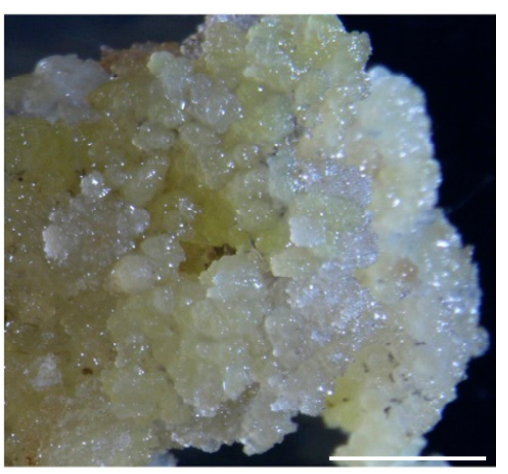

(b)

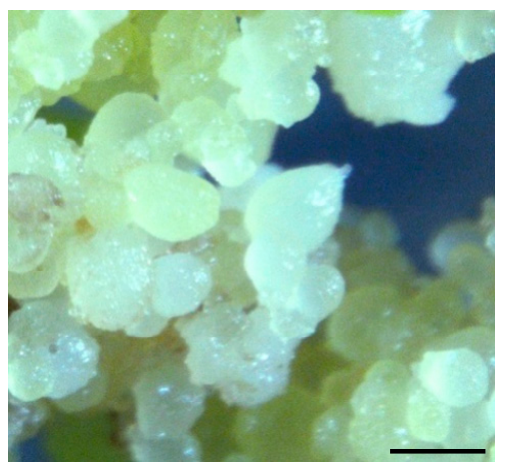

(c)

Figure 1. Samples used for proteomic assays: (a) Nonembryogenic calli; (b) Primary embryogenic calli; (c) Globular embryos. Bar $(\mathbf{a}, \mathbf{b})=2.5 \mathrm{~mm}$; bar $(\mathbf{c})=0.5 \mathrm{~mm}$.

\subsection{TMT-Based Quantitative Proteomic Basis Data Analysis and Overall Protein Identification}

TMT-based quantitative proteomics was conducted to assess protein changes among NEC, PEC and GEs in cotton. Pair wise Pearson's correlation coefficients displayed sufficient reproducibility of this experiment (Figure 2a). After quality validation, a total of 360,720 (74,579 matched) spectra were obtained. Of these spectra, 45062 identified peptides (27,673 unique peptides) and 9369 identified proteins (6730 quantified proteins) were detected (Table 1), and the average peptides mass error was $<10 \mathrm{ppm}$, indicating a high mass accuracy of the MS data (Figure $2 \mathrm{~b}$ ). The lengths of most identified peptides were 8 to 20 amino acid residues (Figure 2c), suggesting that our sampling met the required standard. The detail information of identified proteins, including protein accession, protein description, gene name, peptide number, matching scores, carried charges and delta mass, is shown in Supplementary Table S1.

To further understand their functions, all identified proteins were annotated according to different categories, including subcellular localizations, Gene Ontology (GO) terms, Kyoto Encyclopedia of Genes and Genomes (KEGG) pathways, predicted functional domains and other data. The detailed information of all identified proteins is listed in Supplementary Table S1. 


\begin{tabular}{|c|c|c|c|c|c|c|c|c|c|}
\hline \multicolumn{7}{|c|}{ Pearson's correlation of quantitation } \\
\hline & NEC1 & NEC2 & NEC3 & PEC1 & PEC2 & PEC3 & GE1 & GE2 & GE3 \\
\hline NEC1 & 1 & 0.94 & 0.94 & -0.37 & -0.31 & -0.41 & -0.77 & -0.76 & -0.75 \\
\hline NEC2 & 0.94 & 1 & 0.94 & -0.37 & -0.31 & -0.42 & -0.77 & -0.76 & -0.75 \\
\hline NEC3 & 0.94 & 0.94 & 1 & -0.36 & -0.3 & -0.4 & -0.78 & -0.77 & -0.76 \\
\hline PEC1 & -0.37 & -0.37 & -0.36 & 1 & 0.85 & 0.88 & 0.13 & 0.13 & 0.11 \\
\hline PEC2 & -0.31 & -0.31 & -0.3 & 0.85 & 1 & 0.86 & 0.05 & 0.05 & 0.03 \\
\hline PEC3 & -0.41 & -0.42 & -0.4 & 0.88 & 0.86 & 1 & 0.18 & 0.18 & 0.15 \\
\hline GE1 & -0.77 & -0.77 & -0.78 & 0.13 & 0.05 & 0.18 & 1 & 0.93 & 0.92 \\
\hline GE2 & -0.76 & -0.76 & -0.77 & 0.13 & 0.05 & 0.18 & 0.93 & 1 & 0.92 \\
\hline GE3 & -0.75 & -0.75 & -0.76 & 0.11 & 0.03 & 0.15 & 0.92 & 0.92 & 1 \\
\hline
\end{tabular}

(a)

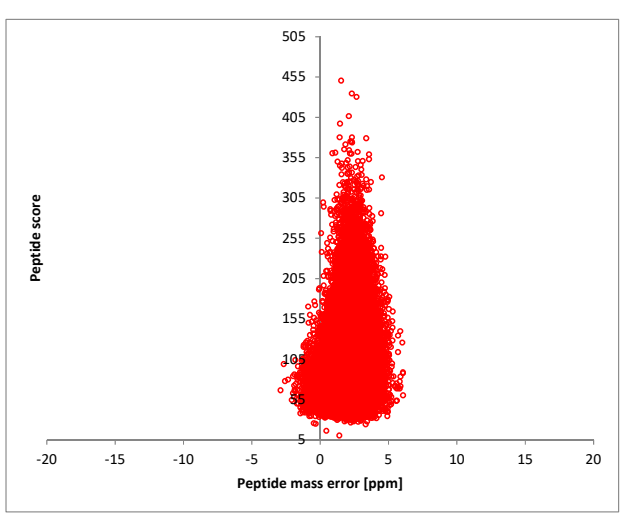

(b)

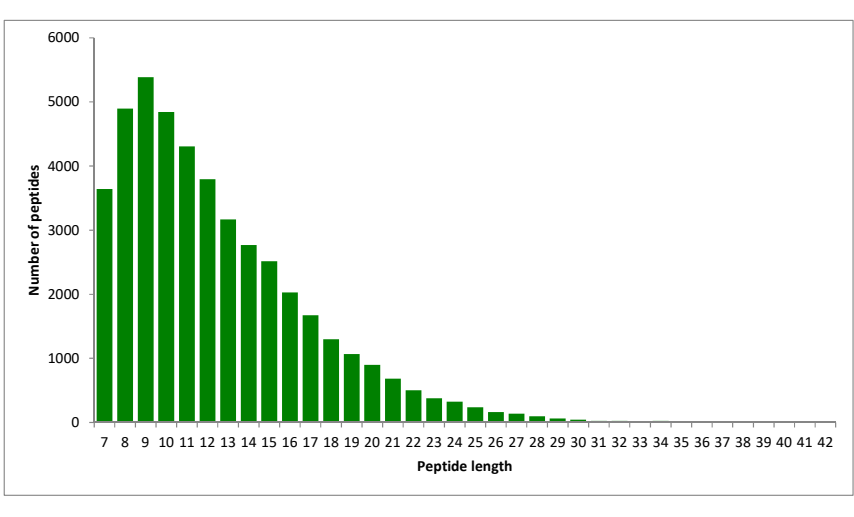

(c)

Figure 2. Experimental strategy for quantitative proteome analysis and quality control validation of MS data: (a) Mass delta of all identified peptides; (b) Average peptide mass error; (c) Length distribution of all identified peptides. NEC: Nonembryogenic calli; PEC: Primary embryogenic calli; GE: Globular embryos. Each staged sample was prepared for three biological replicates.

Table 1. MS/MS spectrum database search analysis summary.

\begin{tabular}{cccccc}
\hline Total Spectrum & Matched Spectrum & Peptides & Unique Peptides & Identified Proteins & Quantifiable Proteins \\
\hline 360,720 & $74,579(20.7 \%)$ & 45,062 & 27,673 & 9369 & 6730 \\
\hline
\end{tabular}

\subsection{Enrichment of the Chloroplast Subcellular Location and GO Functional Classification of All} Identified Proteins

To characterize the subcellular locations and functions of the identified differential proteins among NEC, PEC and GEs in cotton, subcellular locations and GO functional classification were performed (Figure 3; Supplementary Table S1). Subcellular distribution predictions (Figure 3a) showed that the identified proteins were distributed predominantly in chloroplast $(31.10 \%)$, cytoplasm (25.75\%) and nucleus $(23.07 \%)$ during the transformation periods of somatic embryogenesis. Significantly, the highest proportion of differential proteins was enriched in chloroplasts, highlighting that this organelle plays an important role in cotton SE. 


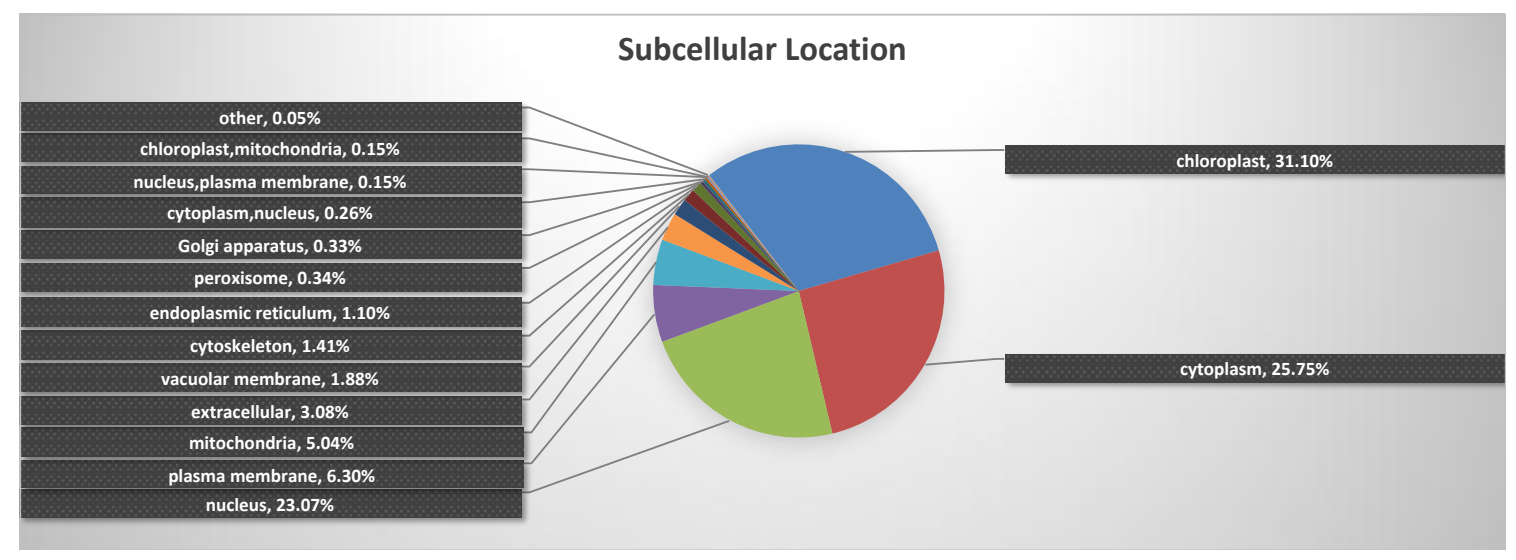

(a)

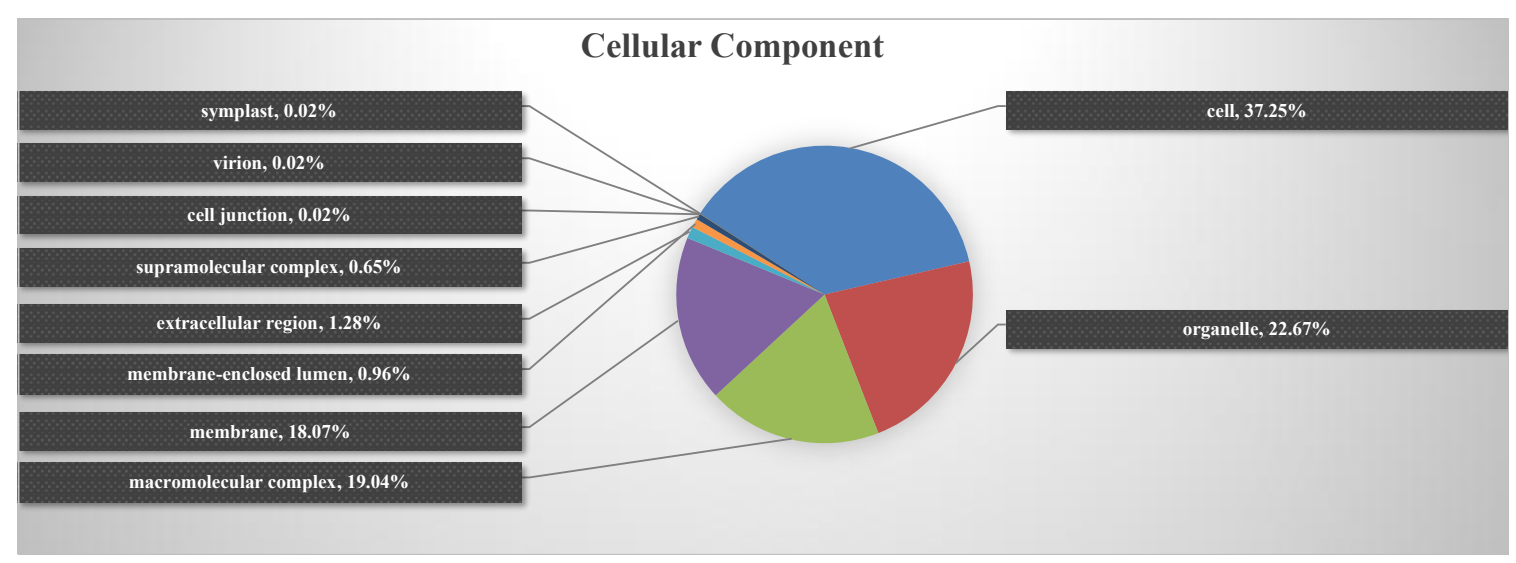

(b)

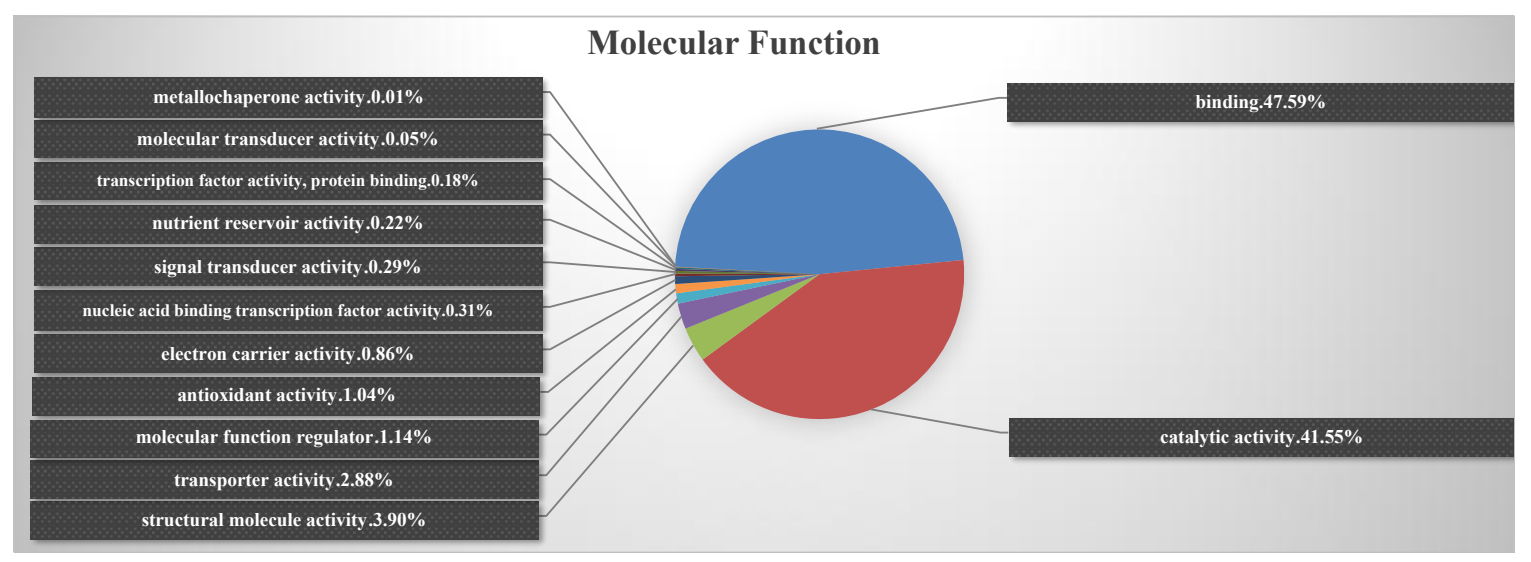

(c)

Figure 3. Cont. 


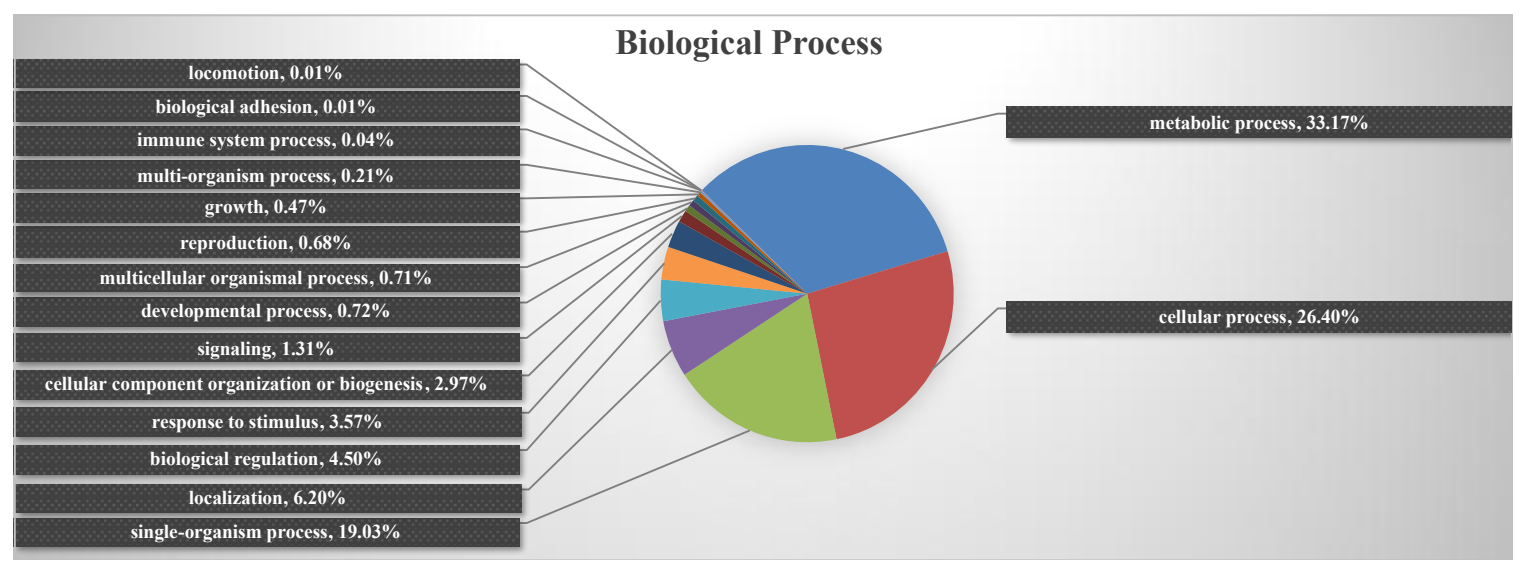

(d)

Figure 3. Subcellular functional annotation and GO functional classification of identified proteins. (a) Subcellular locations of identified proteins; (b) GO annotation in terms of cellular component; (c) GO annotation in terms of molecular function; (d) GO annotation in terms of biological process. GO: Gene Ontology.

The results of cellular component analysis further revealed that $22.67 \%$ of the identified proteins were catalogued in organelles, $19.04 \%$ with macromolecular complexes and $18.07 \%$ with the membrane (Figure 3b). Regarding molecular function, the largest two GO categories, binding and catalytic activity, accounted for 47.59 and $41.55 \%$ of the identified proteins, respectively (Figure 3c). At the biological process level, proteins involved in the metabolic process, cellular process and single-organism process accounted for 33.17, 26.40 and $19.03 \%$ of identified proteins, respectively (Figure 3d). These results demonstrated that the identified proteins are found in multiple cellular components, have diversified molecular functions, and are involved in a variety of biological processes.

\subsection{Identification of Differentially Abundant Proteins}

Differentially abundant proteins were defined as those with a $\geq 2$-fold or $\leq 0.5$-fold change in relative abundance $(p<0.05)$ between PEC and NEC, GEs and PEC, and GEs and NEC. In total, 805, 295 and 1242 DAPs were identified in comparing PEC versus NEC, GEs versus PEC and GEs versus NEC, respectively. In PEC compared with NEC, 805 proteins differentially accumulated were identified, 309 of which were up regulated and 496 of which were down-regulated. Of the 295 DAPs identified between GEs and PEC, 174 and 121 proteins were up- and down regulated in GEs, respectively. Of 1242 proteins differentially accumulated in GEs compared to NEC, 584 and 658 proteins were up- and down regulated, respectively (Figure 4a; Supplementary Table S2).

To identify the commonly and specifically changed proteins between PEC and NEC, GEs and PEC or between GEs and NEC, a Venn diagram was generated (Figure 4b). It clearly showed that 122 and 29 proteins were specifically expressed in PEC and GE processes, respectively, and 85 common proteins (25 and 60) were involved in both PEC and GE.

To investigate the overall dynamics of proteome changes in SEM, we performed eight types of protein expression pattern analyses for the DAPs identified in NEC, PEC and GEs (Figure 4c). These analyses suggested protein expression patterns including down- to up regulation, up- to down regulation, down- to down regulation, up- to up regulation, down- to constant-regulation, up- to constant-regulation, constant- to down regulation and constant- to up regulation. 


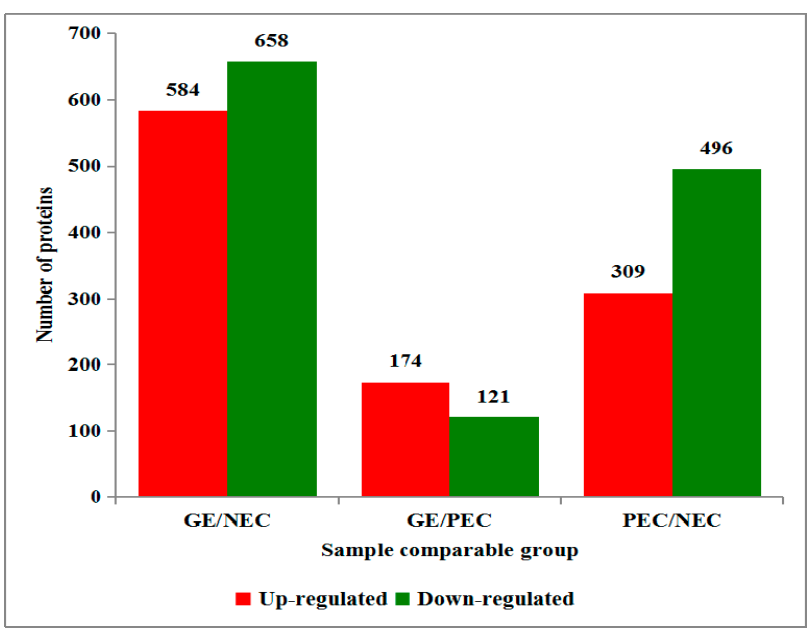

(a)

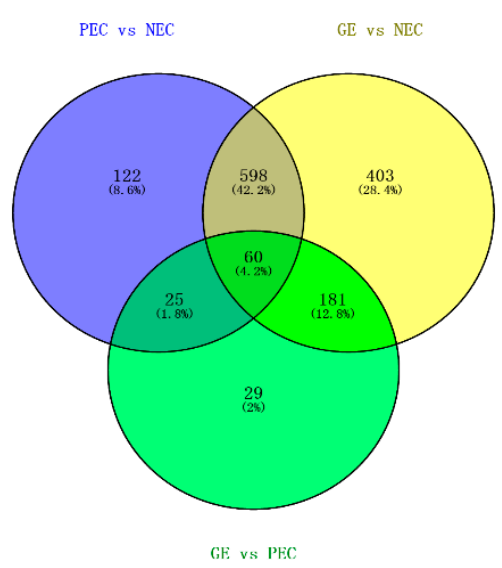

(b)

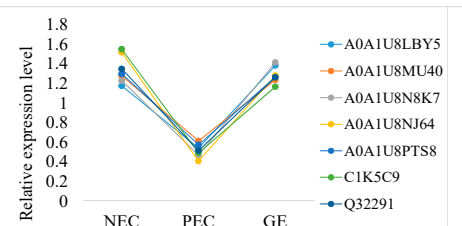

Somatic embryogenesis in different periods

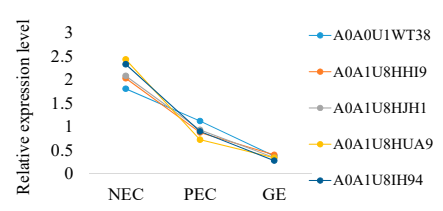

Somatic embryogenesis in different periods

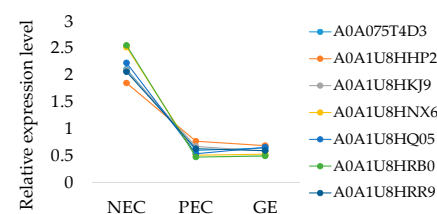

Somatic embryogenesis in different periods

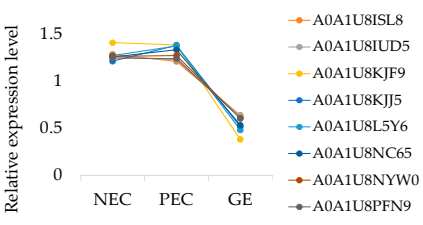

Somatic embryogenesis in different periods

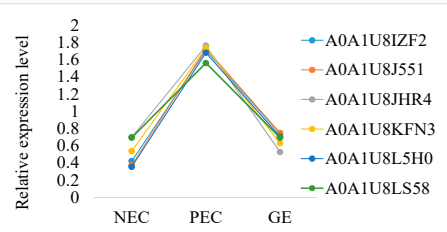

Somatic embryogenesis in different periods

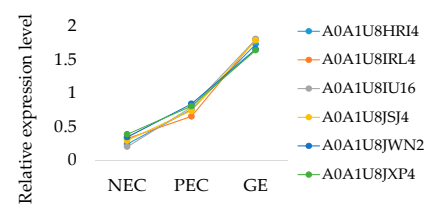

Somatic embryogenesis in different periods

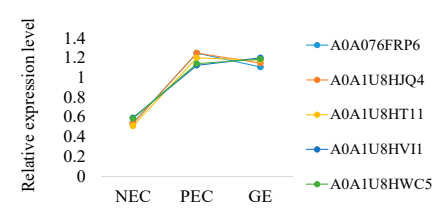

Somatic embryogenesis in different periods

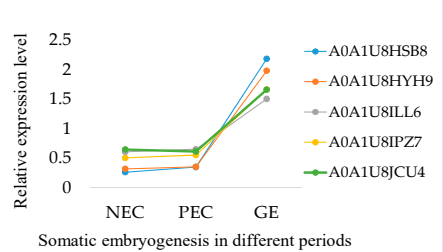

(c)

Figure 4. Distribution of differentially accumulated proteins (DAPs): (a) Number of up(red)- and down(green)-regulated DAPs in GE vs. NEC, GE vs. PEC and PEC vs. NEC; (b) Venn diagram to show the distribution of DAPs between PEC vs. NEC (blue circle), GE vs. PEC (yellow circle) and GE vs. NEC (green circle). (c) Expression patterns of DAPs. NEC: Nonembryogenic calli; PEC: Primary embryogenic calli; GE: Globular embryos. 


\subsection{Enrichment Analysis of DAPs in GO, KEGG and Protein Domain}

In total, 1418 proteins (nonrepetitive DAPs) were differentially accumulated and significantly regulated by the NEC, PEC and GEs under the given culture conditions (Supplementary Table S2/Total DAPs). The biological functions of the DAPs could also be identified by their GO terms, KEGG pathways and protein domain enrichment, as summarized in Figures 5-7.

\subsubsection{Enrichment Cluster Analysis of DAPs between the Groups in GO Terms}

In the different GO functional classifications, we carried out comparative cluster analysis between the sample groups, indicating the change of the co-expression trends of different proteins between the groups.

\section{The Enzyme Metabolism Activity of Molecular Function Category in Cotton SE}

For up-regulated DAPs, 'protein dimerization activity' and 'protein heterodimerization activity' showed a certain degree of enrichment in PEC versus NEC, GE versus PEC and GE versus NEC, especially in GE versus NEC. 'DNA helicase activity' and 'helicase activity' were functional categories which lower in GE versus NEC compared to PEC versus NEC. The up regulation of 'peroxiredoxin activity' and 'nutrient reservoir activity' in GE versus PEC was greater than in GE versus NEC, indicating that the enzyme and nutritional protein activities were higher in GE (Figure 5a). Most of the differential proteins are clearly clustered among the down regulated proteins. Four DAPs of peptidase-related protein activity, proteins from 'hydrolase activity' to 'hydrolase activity, hydrolyzing O-glycosyl compounds' and other enzyme activity were significantly down regulated in PEC versus NEC, but the enrichment of these DAPs was not significant in GE versus PEC; there were various degree of enrichment in GE versus NEC. Additionally, 'glutamate dehydrogenase (NAD+) activity', two proteins of 'oxidoreductase activity' and 'phosphoenolpyruvate carboxykinase (ATP) activity' accumulated to a certain extent in GE versus PEC (Figure 5a).

The results above indicated that enzyme metabolism activity affected the SE of cotton, with dynamic features in NEC, PEC, and GE.

\section{The Photosynthesis-Related Proteins of the Cellular Component Category in Cotton SE}

In the cellular component category of PEC versus NEC and GE versus PEC, a large number of DAPs were clustered in photosynthesis-related cellular components and proteins from 'plastid thylakoid' to 'photosystem I', indicating a significant decrease of photosynthesis in PEC versus NEC. Furthermore, in GE versus PEC, the corresponding photosynthetic cell components showed slightly up regulated enrichment. However, the photosynthetic effect of GE was not higher than NEC; this result showed that the photosynthesis-related DAPs of the cell component classification in GE versus NEC were concentrated in the down regulated expression region (Figure 5b). Additionally, the DAPs' of expression pattern from 'photosynthetic membrane' to 'photosystem II', photosynthesis-related proteins' was similar to the above results in that there was significant down regulation in PEC versus NEC (Figure 5b).

The analysis above showed that photosynthesis is a critical process involved in SE of cotton, which is consistent with our subcellular localization results.

The Regulation, Response and Metabolism-related Proteins of the Biological Process Category in Cotton SE

Proteins related to 'lipid transport', 'reproductive system development', 'DNA metabolic process' and 'regulation' were up regulated with different degrees of enrichment in PEC versus NEC and GE versus NEC. In addition, we also found that from 'amide biosynthetic process' to 'cellular protein metabolic process' proteins in GE versus NEC were uniformly enriched in up regulation (Figure 5c). Furthermore, 'monosaccharide metabolic process', 'hexose metabolic process', glycometabolism related 
proteins and the DAPs from 'aminoglycan catabolic process' to 'cell wall macromolecule metabolic process' were down regulated to different degrees in the three sample groups. Other proteins involved in response regulation were also enriched in the down regulated region in PEC versus NEC and GE versus NEC (Figure 5c).

Interestingly and consistently, the photosynthesis-related proteins in 'photosynthesis, light harvesting' were down regulated in PEC versus NEC and up regulated in GE versus PEC (Figure 5c). The above results demonstrated that SE of cotton might frequently involve proteins associated with environmental stress response, biological regulation, central metabolic processes, and photosynthetic metabolism.

\section{Molecular Function}

$\frac{\text { Up-regulated }}{\mathrm{PEC} / \mathrm{NEC} \text { GE/NEC GE/PEC }} \frac{\text { Dewn-regulated }}{\mathrm{PEC} / \mathrm{NEC} \text { GE/NEC GE/PEC }}$

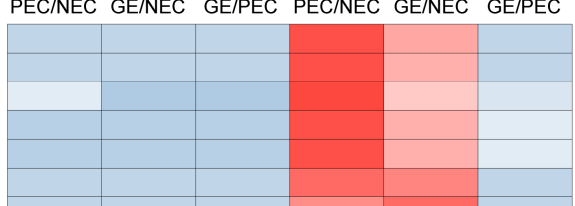

peptidase activity, acting on L-amino acid peptides

peptidase activity

exopeptidase activity

serine hydrolase activity

serine-type peptidase activity

electron transporter, transferring electrons within the cyclic electron transport pathway of photosynthesis activity copper ion binding

oxidoreductase activity, acting on diphenols and related substances as donors, oxygen as acceptor

xyloglucan:xyloglucosyl transferase activity

alpha-L-arabinofuranosidase activity

$\mathrm{NAD}(\mathrm{P}) \mathrm{H}$ dehydrogenase (quinone) activity

hydrolase activity, acting on ester bonds

phosphoric diester hydrolase activity

phosphoric ester hydrolase activity

acid phosphatase activity

chitin binding

chitinase activity

proton-transporting ATPase activity, rotational mechanism

hydrogen-exporting ATPase activity

FMN binding

glutamate dehydrogenase (NAD+) activity

oxidoreductase activity, acting on the $\mathrm{CH}-\mathrm{NH} 2$ group of donors, NAD or NADP as acceptor

enzyme inhibitor activity

oxidoreductase activity, acting on the $\mathrm{CH}-\mathrm{NH} 2$ group of donors

phosphoenolpyruvate carboxykinase (ATP) activity

telomeric DNA binding

ATP-dependent DNA helicase activity

protein dimerization activity

protein heterodimerization activity

DNA helicase activity

helicase activity

peroxiredoxin activity

structural molecule activity

structural constituent of ribosome

nucleic acid binding

DNA binding

nutrient reservoir activity

hydrolase activity

antioxidant activity

tetrapyrrole binding

oxidoreductase activity

carboxypeptidase activity

serine-type exopeptidase activity

serine-type carboxypeptidase activity

heme binding

chlorophyll binding

peroxidase activity

oxidoreductase activity, acting on peroxide as acceptor

hydrolase activity, acting on glycosyl bonds

hydrolase activity, hydrolyzing O-glycosyl compounds

(a)

Figure 5. Cont. 


\section{Cellular Component}

\section{$\frac{\text { Up-regulated }}{\mathrm{PEC} / \mathrm{NEC} \text { GE/NEC GE/PEC }} \frac{\text { Down-regulated }}{\mathrm{PEC} / \mathrm{NEC} \text { GE/NEC GE/PEC }}$}
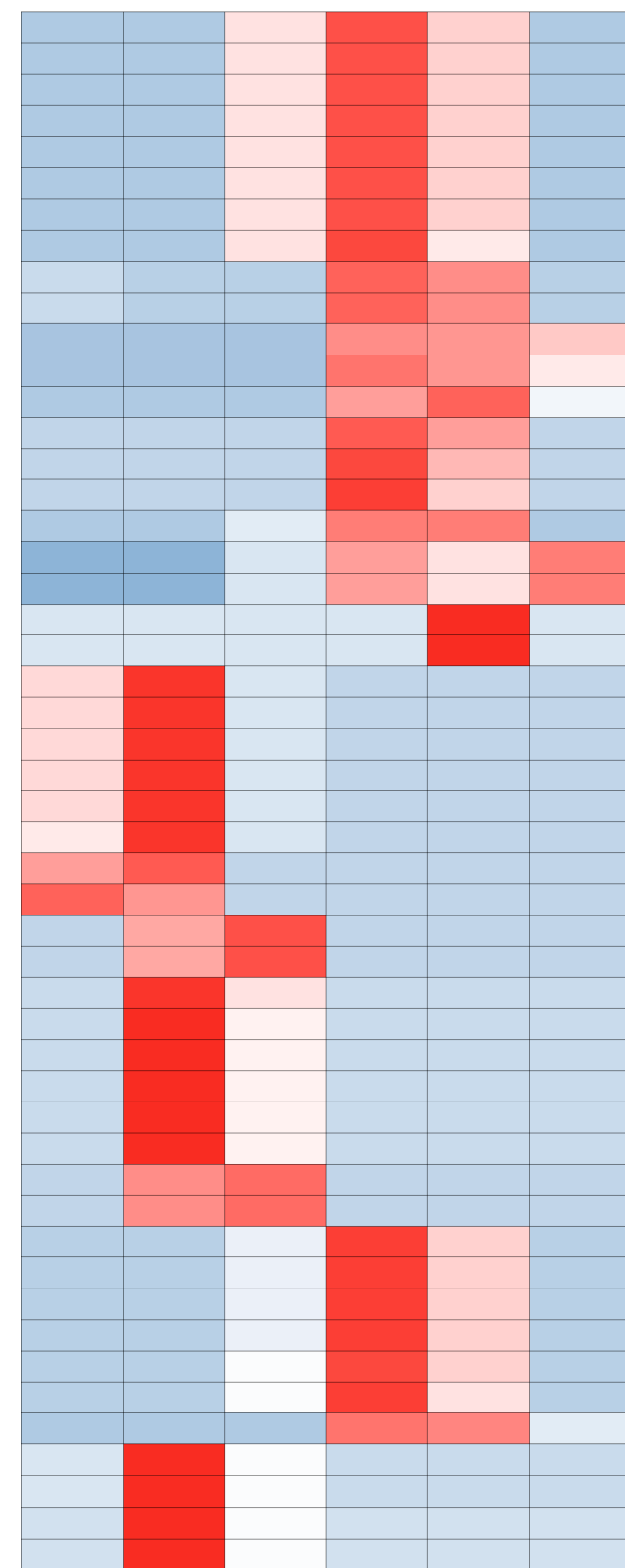

plastid thylakoid

chloroplast thylakoid

plastid thylakoid membrane

chloroplast thylakoid membrane

organelle subcompartment

plastid part

chloroplast part

photosystem I

external encapsulating structure

cell wall

membrane part

apoplast

membrane

cell periphery

extrinsic component of membrane

photosystem II oxygen evolving complex

membrane protein complex

integral component of membrane

intrinsic component of membrane

proton-transporting $V$-type ATPase complex

proton-transporting $\mathrm{V}$-type ATPase, V1 domain

chromatin

DNA packaging complex

protein-DNA complex

nucleosome

chromosomal part

chromosome

nucleus

Ku70:Ku80 complex

cytosolic large ribosomal subunit

cytosolic ribosome

large ribosomal subunit

ribosomal subunit

intracellular ribonucleoprotein complex

ribonucleoprotein complex

ribosome

macromolecular complex

monolayer-surrounded lipid storage body

lipid particle

photosynthetic membrane

thylakoid

thylakoid part

photosystem

thylakoid membrane

photosystem II

extracellular region

intracellular non-membrane-bounded organelle

non-membrane-bounded organelle

organelle

intracellular organelle

(b)

Figure 5. Cont. 


\section{Biological Process}

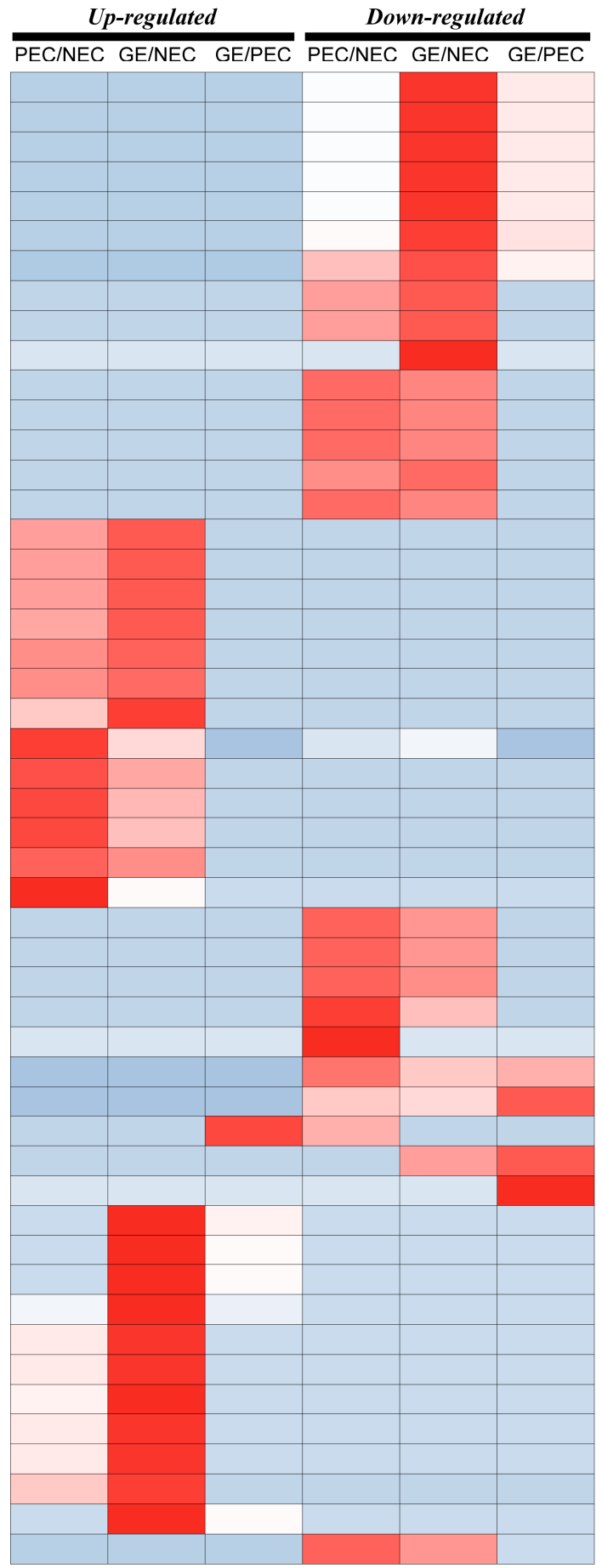

Zscore(-log10(Fisher's exact test p value)

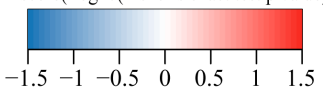

aminoglycan catabolic process

glucosamine-containing compound catabolic process

amino sugar catabolic process

glucosamine-containing compound metabolic process

chitin metabolic process

cell wall macromolecule catabolic process

cell wall macromolecule metabolic process

defense response to fungus

response to fungus

ATP hydrolysis coupled transmembrane transport

defense response to bacterium

response to bacterium

photosynthetic electron transport in photosystem II

defense response to other organism

photosynthetic electron transport chain

regulation of macromolecule biosynthetic process

regulation of cellular biosynthetic process

regulation of cellular macromolecule biosynthetic process

regulation of gene expression

regulation of RNA metabolic process

regulation of nucleobase-containing compound metabolic process

cellular macromolecular complex assembly

lipid transport

nucleic acid metabolic process

trichome differentiation

reproductive system development

telomere organization

DNA metabolic process

cellular detoxification

cellular oxidant detoxification

cell wall polysaccharide metabolic process

pentose metabolic process

proteolysis

monosaccharide metabolic process

hexose metabolic process

photosynthesis, light harvesting

inorganic anion transport

monosaccharide biosynthetic process

amide biosynthetic process

peptide metabolic process

peptide biosynthetic process

cellular macromolecule biosynthetic process

nucleosome organization

DNA packaging

chromatin organization

protein-DNA complex assembly

chromatin assembly or disassembly

DNA conformation change

cellular protein metabolic process

hydrogen peroxide catabolic process

(c)

Figure 5. GO functional cluster of differentially accumulated proteins (DAPs) in PEC vs. NEC, GE vs. PEC and GE vs. NEC: (a) GO functional cluster of DAPs in the molecular function; (b) GO cluster of DAPs in the cellular component; (c) GO functional cluster of DAPs in the biological process. NEC: Nonembryogenic calli; PEC: Primary embryogenic calli; GE: Globular embryos; GO: Gene Ontology. 
2.5.2. Enrichment Analysis in KEGG of the DAPs Involved in Phenylpropanoid Biosynthesis, Nitrogen Metabolism, Photosynthesis and Other Related Biological Processes

Enrichment Analysis in KEGG Clusters of Related Biological Processes among Groups

To further understand the function of SE-related proteins, we analyzed the differences and dynamic changes among groups of rich clustering classes in KEGG pathways. Cluster analysis of up regulated expression pathways showed that protein from 'ribosome biogenesis in eukaryotes' and 'DNA replication' were slightly enriched to varying degrees in PEC versus NEC and GE versus NEC (Figure 6a). In the down regulated enrichment region, multiple types of proteins were enriched in different levels in different sample groups, of which 'phenylpropanoid biosynthesis' and 'nitrogen metabolism' were enriched significantly in PEC versus NEC and GE versus PEC, respectively (Figure 6a). The categories 'photosynthesis-antenna proteins', 'glycolysis/gluconeogenesis' and 'carbon fixation in photosynthetic organisms' were down regulated in PEC versus NEC and up regulated in GE versus PEC (Figure 6a).

Phenylpropanoid biosynthesis and nitrogen metabolism were significantly enriched and photosynthesis was re-enriched. The study suggesting the above biological processes possible involvement in cotton SE transformation.

KEGG Pathway Enrichment Analysis of Related Biological Processes within the Sample Groups

In PEC versus NEC, KEGG pathway enrichment analysis demonstrated that the 'phenylpropanoid biosynthesis', 'photosynthesis', 'glutathione metabolism' and 'glycolysis/gluconeogenesis' were the most significantly affected pathways. A great deal of peroxidase proteins of the phenylpropanoid biosynthesis pathway were down regulated in PEC and NEC. Furthermore, a variety of proteins related to 'photosynthesis' and a slight number of DAPs of the 'glycolysis/gluconeogenesis' pathway were also down-regulated in PEC and NEC. Additionally, the 'glutathione metabolism' pathway was down regulated in PEC and NEC (Figure 6b).

KEGG analysis of GE versus PEC indicated that the enriched pathways of the DAPs were most remarkably associated with 'glutathione metabolism' and 'nitrogen metabolism' pathways, which were both down regulated. Once again, 'photosynthesis-antenna proteins' and 'photosynthesis' were significantly enriched up regulated pathways (Figure 6c).

In addition, DAPs of GE versus NEC were classified into various KEGG pathways, of which 6 metabolic pathways were significantly enriched. Interestingly, the largest number of DAPs was once more enriched in 'phenylpropanoid biosynthesis' and 'photosynthesis' were down-regulated. Moreover, 'ribosome' was up regulated pathways that were also enriched (Figure 6d).

The results of the KEGG pathway analysis further indicated that the three metabolic pathways, including phenylpropanoid biosynthesis, nitrogen metabolism and photosynthesis, are essential for the process of cotton SE transformation. 


\section{KEGG pathway}

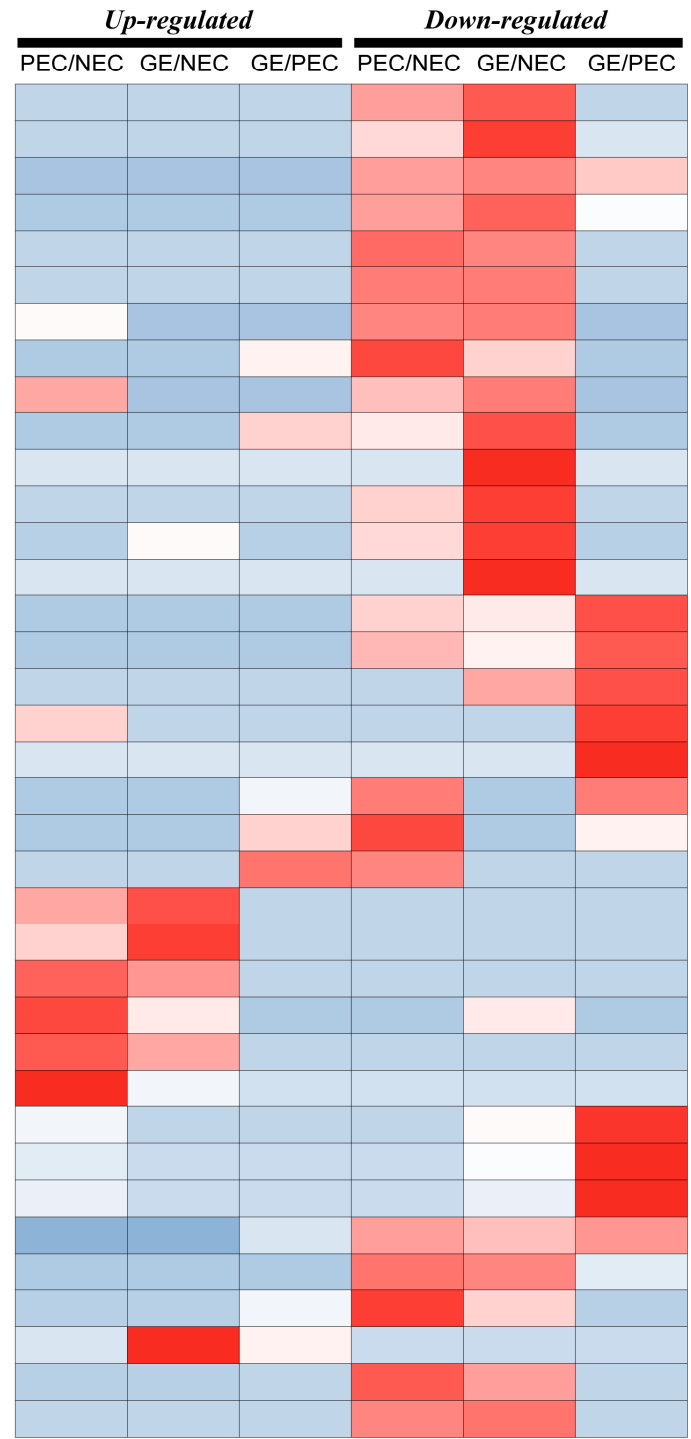

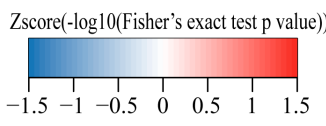

Ubiquinone and other terpenoid-quinone biosynthesis Starch and sucrose metabolism beta-Alanine metabolism

Amino sugar and nucleotide sugar metabolism Glycerolipid metabolism Lysine degradation Tryptophan metabolism Pentose and glucuronate interconversions Linoleic acid metabolism

Cyanoamino acid metabolism Phagosome

Other glycan degradation Sphingolipid metabolism

Ether lipid metabolism

Taurine and hypotaurine metabolism

Butanoate metabolism

Galactose metabolism

Pyruvate metabolism

Carbon metabolism

Glycolysis / Gluconeogenesis

Carbon fixation in photosynthetic organisms

Photosynthesis - antenna proteins

Ribosome biogenesis in eukaryotes

Spliceosome

Non-homologous end-joining

Cutin, suberine and wax biosynthesis

Base excision repair

DNA replication

Nitrogen metabolism

Alanine, aspartate and glutamate metabolism

Arginine biosynthesis

Glutathione metabolism

Biosynthesis of secondary metabolites

Photosynthesis

Ribosome

Phenylpropanoid biosynthesis

Metabolic pathways

(a)

Figure 6. Cont. 


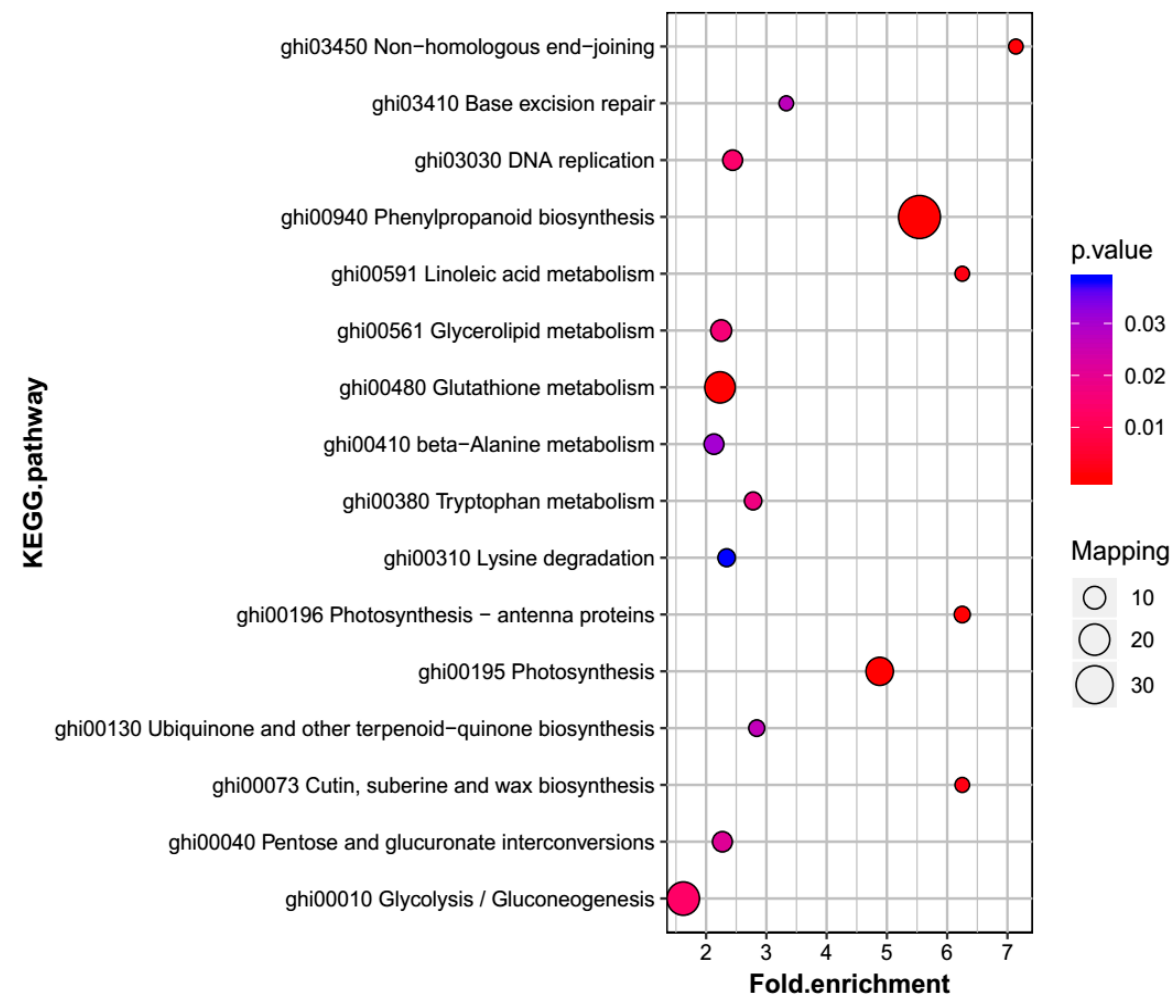

(b)

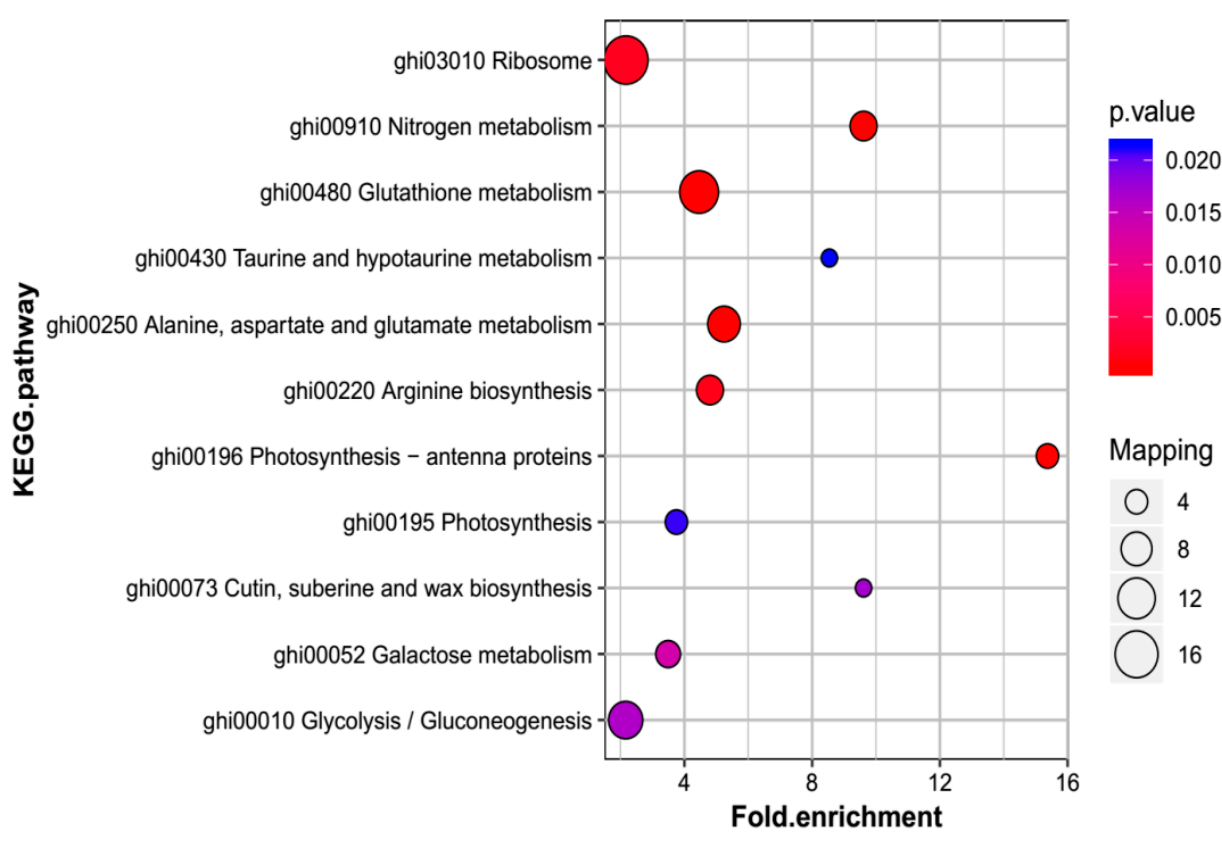

(c)

Figure 6. Cont. 


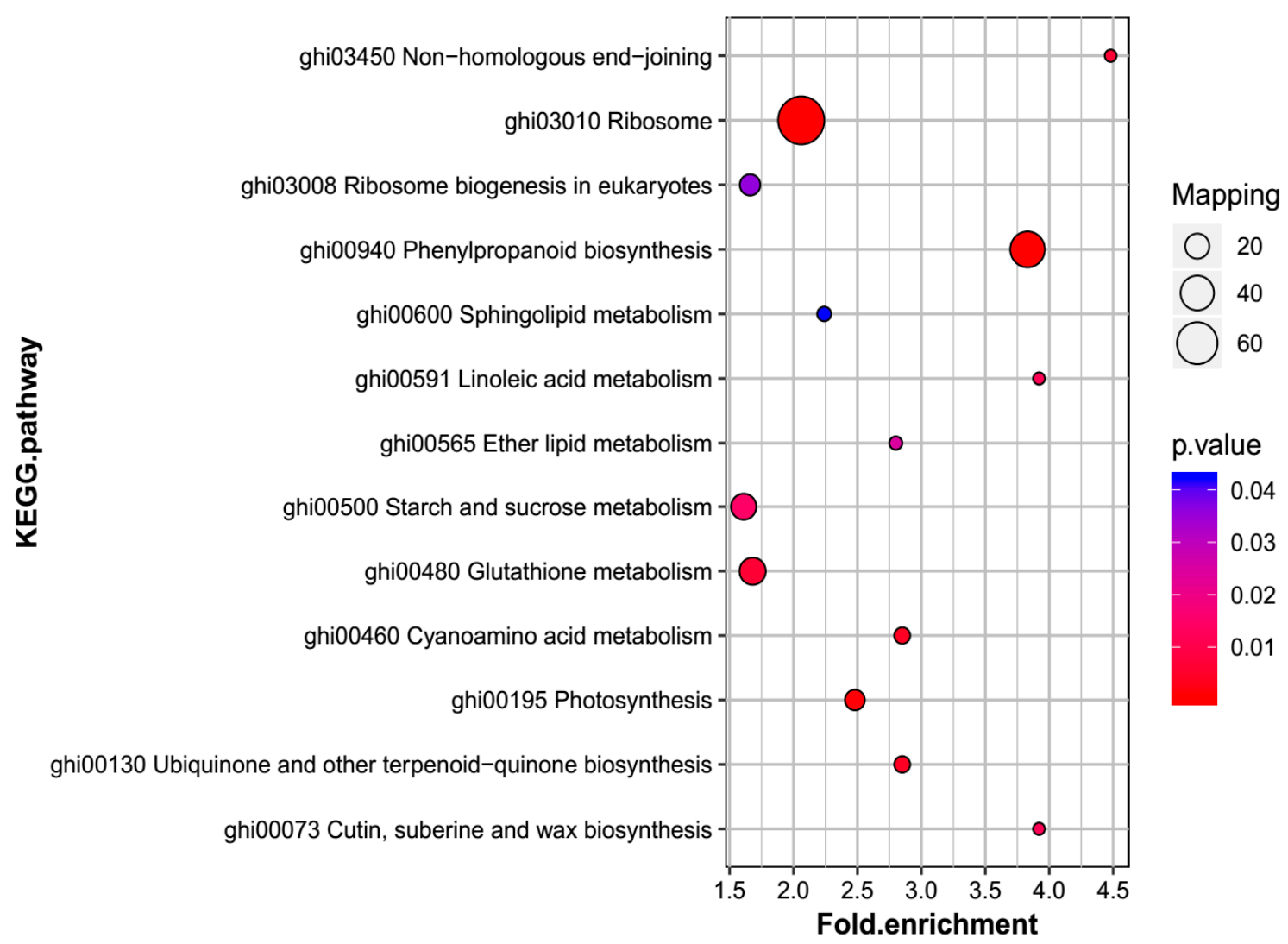

(d)

Figure 6. KEGG cluster and pathway enrichment analysis of DAPs: (a) KEGG clusters in PEC vs. NEC, GE vs. PEC and GE vs. NEC; (b) Pathway enrichment in PEC vs. NEC; (c) Pathway enrichment in GE vs. PEC; (d) Pathway enrichment in GE vs. NEC. The pathway enrichment statistical analysis was performed by Fisher's exact test. The X-axis is folded enrichment; the y-axis is enrichment pathway. The mapping is the protein number. NEC: Nonembryogenic calli; PEC: Primary embryogenic calli; GE: Globular embryos; KEGG: Kyoto encyclopedia of genes and genomes

\subsubsection{Enrichment Cluster Analysis of Differential Proteins Functional Domain}

Domain enrichment analysis of up regulated proteins revealed that 'histone'-related domain, 'ribosomal'-related domain, 'seed maturation protein', 'translation protein SH3-like domain', 'RmlC-like jelly roll fold', 'Cupin 1' and 'RmlC-like cupin domain' were enriched in the three sample groups with different dynamic expression patterns. The degree of enrichment of 'rmlC-like jelly roll fold' and 'cupin 1', seed storage protein-related domain, was extremely high in GE versus PEC (Figure 7). This result indicates that the development of GE requires storage proteins to provide nutrients for the regeneration of somatic embryos. For the down regulated expression region, domains including the 'aspartic peptidase domain' and the 'START-like domain' were abundant in three or two samples groups, including glutathione $S$-transferase domain. Furthermore, domains related to 'haem peroxidase, plant/fungal/bacterial', 'secretory peroxidase', 'aquaporin-like' and 'glycoside hydrolase' were equally enriched in PEC versus NEC and GE versus NEC (Figure 7).

The cluster analysis of dynamic enrichment changes through different functional domains showed that the 'rmlC-like cupin domain', seed maturation protein, glutathione S-transferase and peroxidase-related domain were driving diverse tasks in different development processes of cotton SE. 


\section{Protein domain}

\section{$\frac{\text { Up-regulated }}{\mathrm{PEC} / \mathrm{NEC} \text { GE/NEC GE/PEC } \mathrm{PEC/NEC} \mathrm{GE/NEC} \mathrm{GE/PEC}}$}
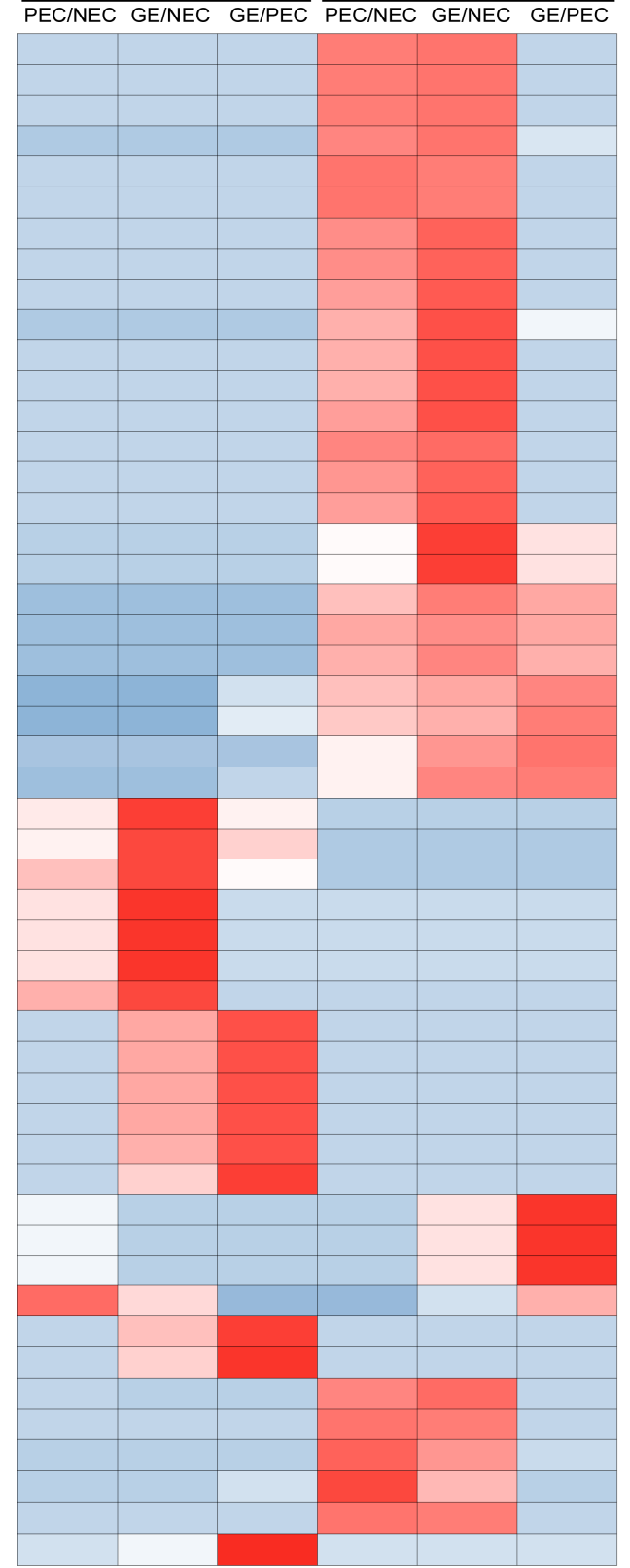

Zscore(-log10(Fisher's exact test p value))

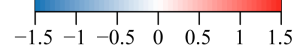

Aspartic peptidase domain

RIpA-like protein, double-psi beta-barrel domain

Peptidase family $\mathrm{A} 1$ domain

Alpha/Beta hydrolase fold

Xylanase inhibitor, C-terminal

Xylanase inhibitor, $\mathrm{N}$-terminal

Glycoside hydrolase, family $3, \mathrm{~N}$-termina

Glycoside hydrolase family $3 \mathrm{C}$-terminal domain

Peptidase C1A, papain C-terminal

Cupredoxin

Phosphatidylinositol-specific phospholipase $\mathrm{C}, \mathrm{X}$ domain

CND41-like

Multicopper oxidase, type 1

PAN/Apple domain

Cathepsin propeptide inhibitor domain (129)

Multicopper oxidase, type 3

Lysozyme-like domain

Glycoside hydrolase, family 19 , catalytic

FAD linked oxidase, $\mathrm{N}$-terminal

CO dehydrogenase flavoprotein-like, FAD-binding, subdomain 2

Berberine/berberine-like

Glutathione S-transferase, N-terminal

Glutathione S-transferase, C-terminal-like

Bet $\mathrm{v}$ I/Major latex protein

START-like domain

Histone $\mathrm{H} 2 \mathrm{~A} / \mathrm{H} 2 \mathrm{~B} / \mathrm{H} 3$

Ribosomal protein $\mathrm{L} 23 / \mathrm{L} 15 \mathrm{e}$ core domain

Histone-fold

Nucleotide-binding alpha-beta plait domain

Ribosomal protein $\mathrm{L} 2$ domain 2

Translation protein $\mathrm{SH} 3$-like domain

Ribosomal protein $\mathrm{L} 6, \mathrm{~N}$-terminal

Ribosomal protein L19, eukaryotic

Ribosomal protein L19/L19e

Ribosomal protein L19/L19e, domain 1

Ribosomal protein L19/L19e, domain 3

Seed maturation protein

Vicilin, $\mathrm{N}$-terminal

Glutamate/phenylalanine/leucine/valine dehydrogenase, C-terminal

$N A D(P)$ binding domain of glutamate dehydrogenase

Glutamate/phenylalanine/leucine/valine dehydrogenase, dimerisation domain

Bifunctional inhibitor/plant lipid transfer protein/seed storage helical domain

Cupin 1

RmIC-like jelly roll fold

Haem peroxidase, plant/fungal/bacterial

Glycoside hydrolase superfamily

Secretory peroxidase

Aquaporin-like

Glycoside hydrolase, catalytic domain

RmlC-like cupin domain

Figure 7. Protein domain enrichment analysis of the differentially accumulated proteins (DAPs) in PEC vs. NEC, GE vs. PEC and GE vs. NEC. NEC: Nonembryogenic calli; PEC: Primary embryogenic calli; GE: Globular embryos.

\subsection{Enrichment Analysis of the Major Biological Process between Different Comparison Groups}

Above all, the significantly enriched GO terms of the biological process in different comparison groups were investigated. In PEC and NEC, the top 5 GO terms were peroxidase-related, further demonstrated the above results that significant enrichment of the phenylpropanoid biosynthesis pathway was observed during the initiation process of SE. In addition, 'photosynthesis' term showed significant changes in the PEC differentiation, promoting cotton SE. In GE and PEC, environmental response and photosynthesis related proteins were presented in the top 12 GO terms, indicating that the abundant abiotic stress and photosynthesis responsive proteins might regulate 
the maturity and development of globular embryos. In GE and NEC, the top 8 GO terms were peroxidase, photosynthesis and environmental response related proteins, being part of an important biological process in the process of cotton somatic embryo transformation. What's more, glutamate dehydrogenase (GDH) is significantly enriched in the molecular function classification of PEC and GE. GDH is one of the main enzymes of nitrogen metabolism and participates in important biological processes of plant SE. These important biological processes throughout the development process suggested that complex regulatory networks are involved in the cotton SE process (Figure 8).

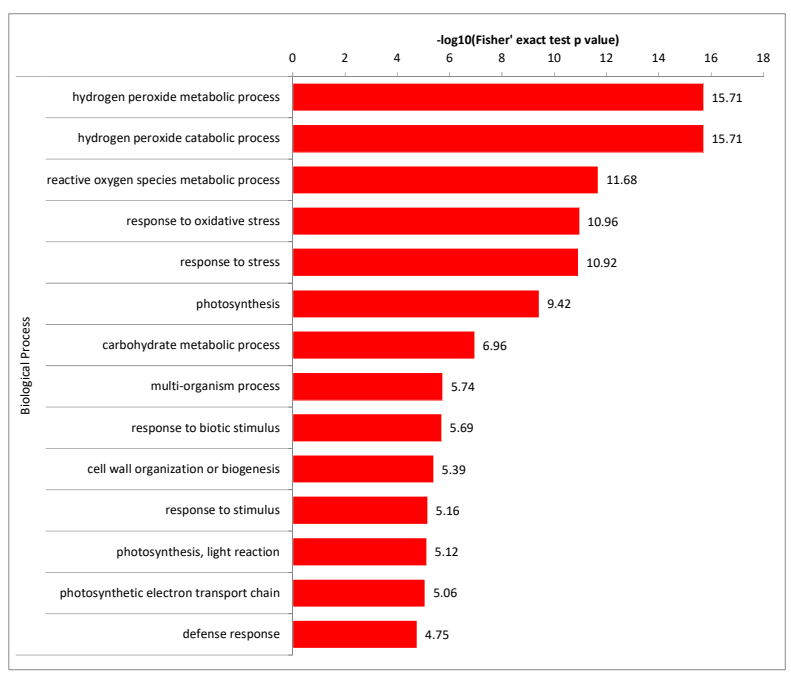

(a)

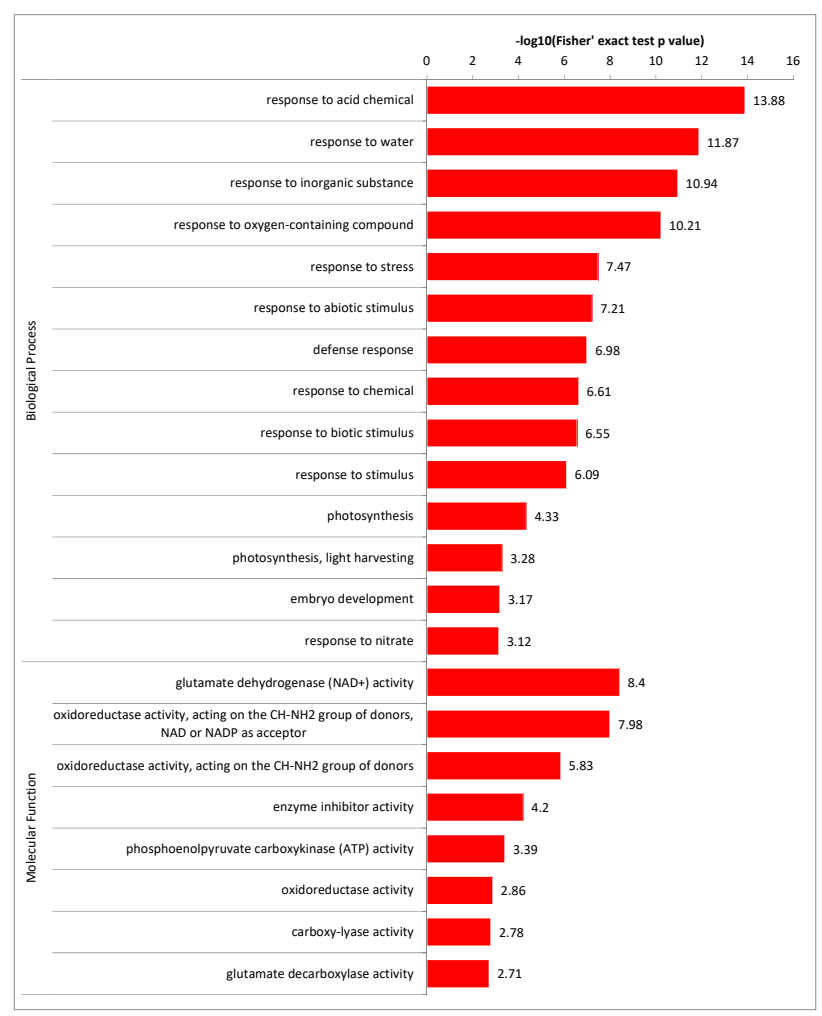

(b)

Figure 8. Cont. 


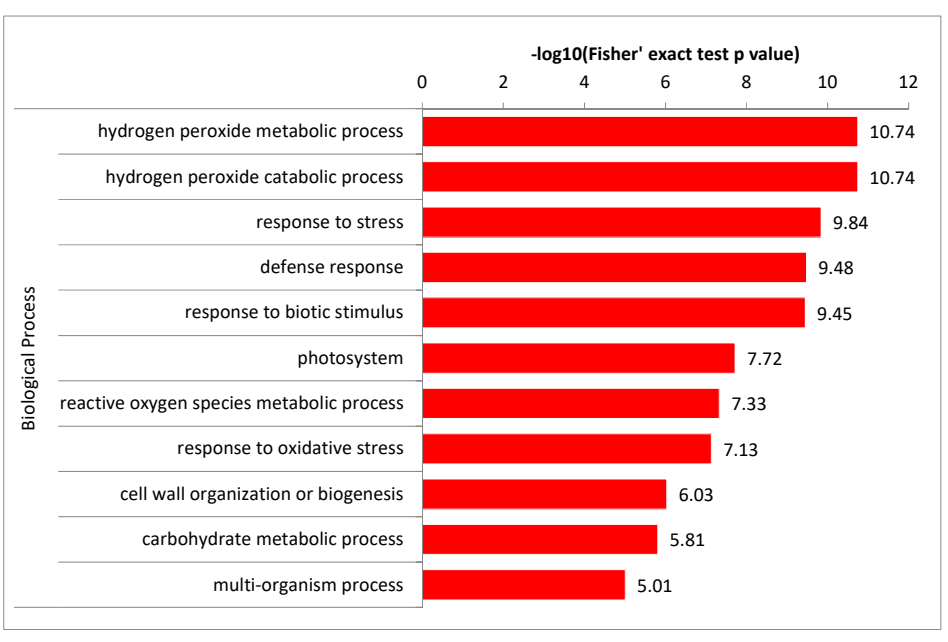

(c)

Figure 8. GO terms of differentially accumulated proteins (DAPs) in the biological process and the molecular function: (a) The biological process of DAPs in PEC vs. NEC; (b) The biological process and the molecular function of DAPs in GE vs. PEC; (c) The biological process of DAPs in GE vs. NEC. NEC: Nonembryogenic calli; PEC: Primary embryogenic calli; GE: Globular embryos; GO: Gene Ontology.

\subsection{Several Major DAPs are Associated with SE Regulation and Modification}

SE of cotton is regulated by many factors. The GO and KEGG enrichment analysis showed that peroxidase, photosynthesis-related proteins, stress-responsive proteins, amino acid metabolism-related proteins and other energy metabolism enriched proteins all play an important role in the process of cotton SE. Furthermore, we comprehensively explored and analyzed differentially abundant proteins in cotton SE involving hormone signal response/signaling transduction, transcription/posttranscription and modification regulation (Table 2).

Table 2. Significantly representative SE regulatory DAPs in PEC vs. NEC, GE vs. PEC and GE vs. NEC.

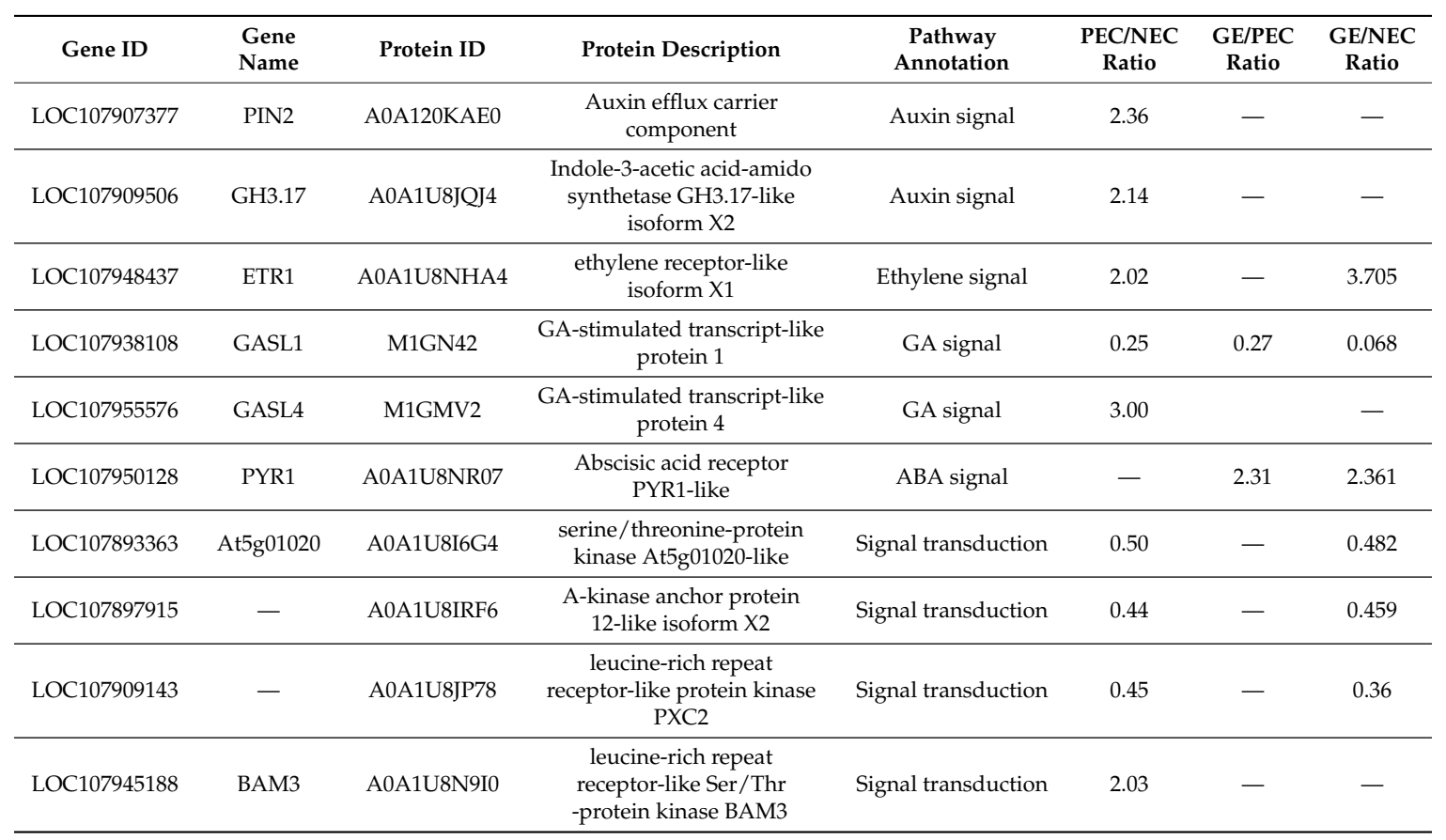


Table 2. Cont

\begin{tabular}{|c|c|c|c|c|c|c|c|}
\hline Gene ID & $\begin{array}{l}\text { Gene } \\
\text { Name }\end{array}$ & Protein ID & Protein Description & $\begin{array}{c}\text { Pathway } \\
\text { Annotation }\end{array}$ & $\begin{array}{l}\text { PEC/NEC } \\
\text { Ratio }\end{array}$ & $\begin{array}{l}\text { GE/PEC } \\
\text { Ratio }\end{array}$ & $\begin{array}{c}\text { GE/NEC } \\
\text { Ratio }\end{array}$ \\
\hline LOC107935259 & PCKA & A0A1U8M980 & $\begin{array}{c}\text { phosphoenolpyruvate } \\
\text { carboxykinase [ATP]-like }\end{array}$ & Signal transduction & 2.08 & 0.38 & - \\
\hline LOC107905700 & PFK & A0A1U8JGW8 & $\begin{array}{c}\text { ATP-dependent } \\
\text { 6-phosphofructokinase }\end{array}$ & Signal transduction & - & 2.55 & 2.504 \\
\hline LOC107943957 & PV42A & A0A1U8N623 & $\begin{array}{l}\text { SNF1-related protein kinase } \\
\text { regulatory subunit } \\
\text { gamma-like PV42a }\end{array}$ & Signal transduction & - & 2.83 & 2.757 \\
\hline LOC107916423 & RHN1 & A0A1U8KFK5 & $\begin{array}{l}\text { ras-related protein } \\
\text { RHN1-like }\end{array}$ & Signal transduction & - & 0.47 & 0.333 \\
\hline LOC107889787 & - & A0A1U8HV05 & Embryonic protein DC-8-like & $\begin{array}{c}\text { Somatic } \\
\text { embryogenesis } \\
\text { related proteins }\end{array}$ & - & 3.58 & 4.522 \\
\hline LOC107937048 & Lea2A-A & Q03791 & $\begin{array}{l}\text { Embryogenesis abundant } \\
\text { protein }\end{array}$ & $\begin{array}{l}\text { Somatic } \\
\text { embryogenesis } \\
\text { related proteins }\end{array}$ & - & 4.42 & 4.746 \\
\hline LOC107941722 & WOX9 & A0A1U8MVD7 & $\begin{array}{l}\text { WUSCHEL-related } \\
\text { homeobox 9-like }\end{array}$ & Transcription factor & 2.58 & - & - \\
\hline LOC107924015 & PHL1 & A0A1U8L8P3 & Protein PHR1-LIKE 1-like & Transcription factor & 0.15 & - & 0.166 \\
\hline LOC107891610 & At1g07170 & A0A1U8I119 & $\begin{array}{c}\text { PHD finger-like } \\
\text { domain-containing protein } \\
5 \mathrm{~B}\end{array}$ & Zinc finger & 3.49 & - & 4.21 \\
\hline LOC107909066 & NERD & A0A1U8JUI6 & $\begin{array}{c}\text { zinc finger } \mathrm{CCCH} \\
\text { domain-containing protein } \\
\text { 19-like isoform } \mathrm{X} 2\end{array}$ & Zinc finger & 2.03 & - & - \\
\hline LOC107927097 & TAF15B & A0A1U8LG36 & $\begin{array}{l}\text { transcription TFIID subunit } \\
\text { 15b-like }\end{array}$ & Zinc finger & 0.44 & - & - \\
\hline LOC107962890 & ZHD5 & A0A1U8PUW9 & $\begin{array}{l}\text { zinc-finger homeodomain } \\
\text { protein 5-like }\end{array}$ & Zinc finger & - & 2.93 & 5.554 \\
\hline LOC107890886 & AGO1 & A0A1U8HY77 & $\begin{array}{l}\text { protein argonaute 1-like } \\
\text { isoform X2 }\end{array}$ & $\begin{array}{l}\text { Posttranscriptional } \\
\text { regulation }\end{array}$ & 8.44 & - & 6.734 \\
\hline LOC107906203 & AGO4 & A0A1U8JEA7 & protein argonaute 4-like & $\begin{array}{l}\text { Posttranscriptional } \\
\text { regulation }\end{array}$ & 2.38 & - & 2.426 \\
\hline LOC107962954 & HEN1 & A0A1U8PXD5 & $\begin{array}{c}\text { small RNA } \\
\text { 2'-O-methyltransferase-like } \\
\text { isoform X4 }\end{array}$ & $\begin{array}{l}\text { Posttranscriptional } \\
\text { regulation }\end{array}$ & 2.06 & - & - \\
\hline LOC107891032 & IDM1 & A0A1U8HYR9 & $\begin{array}{l}\text { increased DNA methylation } \\
\text { 1-like isoform X4 }\end{array}$ & $\begin{array}{l}\text { Modification-related } \\
\text { protein }\end{array}$ & 2.62 & 0.49 & - \\
\hline LOC107906306 & MMT1 & A0A1U8JEK1 & $\begin{array}{c}\text { Methionine } \\
\text { S-methyltransferase }\end{array}$ & $\begin{array}{l}\text { Modification-related } \\
\text { protein }\end{array}$ & 0.46 & - & 0.458 \\
\hline
\end{tabular}


Table 2. Cont.

\begin{tabular}{|c|c|c|c|c|c|c|c|}
\hline Gene ID & $\begin{array}{l}\text { Gene } \\
\text { Name }\end{array}$ & Protein ID & Protein Description & $\begin{array}{l}\text { Pathway } \\
\text { Annotation }\end{array}$ & $\begin{array}{l}\text { PEC/NEC } \\
\text { Ratio }\end{array}$ & $\begin{array}{c}\text { GE/PEC } \\
\text { Ratio }\end{array}$ & $\begin{array}{c}\text { GE/NEC } \\
\text { Ratio }\end{array}$ \\
\hline LOC107916882 & IAMT1 & A0A1U8KGS5 & $\begin{array}{c}\text { indole-3-acetate } \\
\text { O-methyltransferase } 1\end{array}$ & $\begin{array}{l}\text { Modification-related } \\
\text { protein }\end{array}$ & 2.32 & - & - \\
\hline LOC107960303 & - & A0A1U8PLN7 & $\begin{array}{c}\text { Acetyltransferase component } \\
\text { of pyruvate dehydrogenase } \\
\text { complex }\end{array}$ & $\begin{array}{l}\text { Modification-related } \\
\text { protein }\end{array}$ & 0.48 & - & 0.404 \\
\hline LOC107947121 & UBR7 & A0A1U8NDR8 & $\begin{array}{l}\text { putative E3 ubiquitin-protein } \\
\text { ligase UBR7 }\end{array}$ & $\begin{array}{l}\text { Modification-related } \\
\text { protein }\end{array}$ & 2.90 & - & 2.679 \\
\hline LOC107898863 & CYP86B1 & A0A1U8IP72 & Cytochrome P450 86B1-like & Fatty acid & 4.51 & - & 2.388 \\
\hline LOC107922796 & CYP86A8 & A0A1U8L513 & Cytochrome P450 86A8-like & Fatty acid & 2.02 & - & - \\
\hline LOC107915850 & PIP2-5 & A0A1U8KIL6 & probable aquaporin PIP2-5 & Aquaporins & - & 2.58 & - \\
\hline LOC107898442 & TIP3-2 & A0A1U8IU16 & probable aquaporin TIP3-2 & Aquaporins & - & 2.29 & 9.086 \\
\hline LOC107963873 & GhPIP2;10 & D8FSK4 & Aquaporin PIP210 & Aquaporins & 0.14 & - & 0.102 \\
\hline- & GhTIP1;4 & D8FSK6 & Aquaporin TIP14 & Aquaporins & 0.20 & - & 0.195 \\
\hline $\begin{array}{l}\text { LOC107934987 } \\
\text { LOC107944588 }\end{array}$ & PIP1;4 & G8XV51 & PIP protein & Aquaporins & 0.22 & - & 0.109 \\
\hline
\end{tabular}

DAPs: differentially accumulated proteins; NEC: Nonembryogenic calli; PEC: Primary embryogenic calli; GE: Globular embryos; GO: Gene Ontology.

\subsection{Comparative and Complementary Proteome of the Candidate DAPS}

To complement the changes in abundance at the transcriptional level and confirm the authenticity and accuracy of the proteomic analysis, we analyzed ten candidate DAPs in NEC and PEC. Eight out of ten genes under this analysis showed positive correlation between the expression levels of protein and mRNA, indicating that most proteins were regulated directly at the transcription level. For the other two DAPs, negative correlation between their expression levels of protein and mRNA was observed, suggesting that their protein levels might be depended not only on the transcript level but also on the post-translational level (Figure 9). 


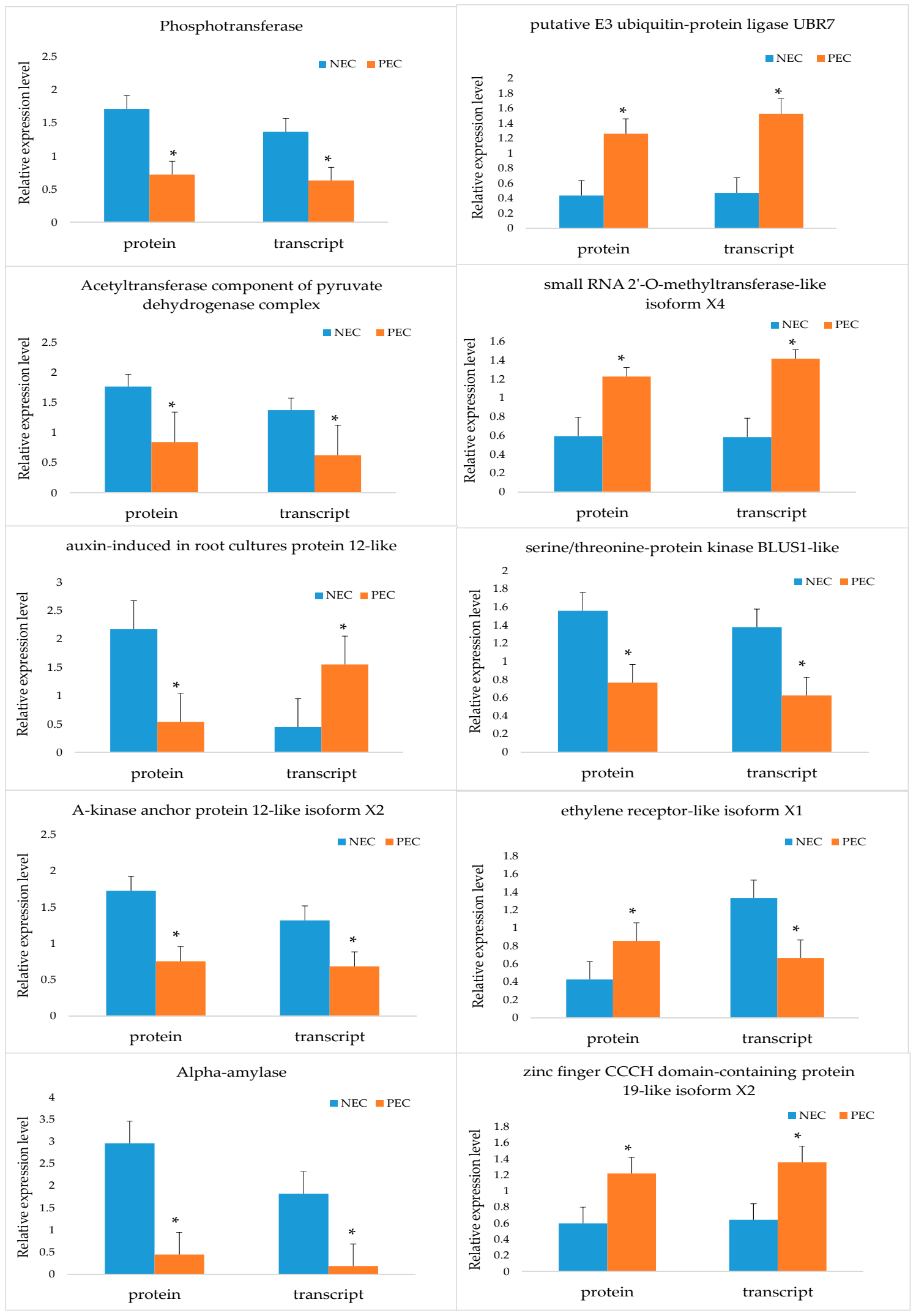

Figure 9. Comparative and complementary proteome of the candidate DAPs in stage of NEC and PEC. Significant differences in expression level were indicated by “*”. DAPs: differentially accumulated proteins; NEC: Nonembryogenic calli; PEC: Primary embryogenic calli; GE: Globular embryos. 


\section{Discussion}

Proteomics analyses have long been recognized as a useful tool to dissect the molecular mechanisms of SE. The effectiveness of this technique is strongly dependent on the applied technique of the proteomics analysis system and the experimental system. Proteomics analyses for the somatic embryogenesis in Pinus nigra Arn. [42] and Phoenix dactylifera L. [43] have been previously performed. In this study, we performed quantitative proteomics analysis using the advanced EASY-nLC 1000 UPLC system based on the high-throughput TMT-labeling quantitative detection technique, and we consequently identified 9369 proteins for our samples. Thus, our new study significantly improved the resolution. TMT is advantageous and offers greater sensitivity for the analysis of cotton SE proteomic dynamics than previous methods. Furthermore, most previous studies have focused on the molecular mechanisms of regulation in the late stage of somatic embryogenesis, and little is known about protein regulation and metabolism in the early stage of embryogenesis. In the isobaric tags for relative and absolute quantitation (iTRAQ) proteomics analysis of Ge [11], 6318 proteins were identified in somatic spherical embryo and cotyledon embryo. Subsequently, Zhu [44] identified 5892 proteins related to SE through iTRAQ technology. In our study, a total of 9369 proteins were identified in stages of NEC, PEC and somatic embryos' initial development period of GEs by TMT-labeling quantitative detection technique. Through identification and annotation of DAPs, we uncovered the key genes/proteins and pathways involved in the critical initial stage of cotton SE. The results generated in this study provide a valuable foundation for further investigation of the roles of DAPs during the expression of totipotency in cotton SE.

\subsection{DAPs Enriched in Crucial Biological Processes Associated with Cotton SE}

\subsubsection{Peroxidase Proteins Involved in Phenylpropanoid Biosynthesis Affect SE}

Recently, a proteomic analysis of the somatic embryogenesis induction stage of Medicago truncatula revealed that peroxidase accumulates by day 5 after the induction of somatic embryogenesis and increases four-fold by day 14 [45]. Peroxidase is known to take part in diverse plant processes, such as auxin metabolism, cell wall elongation and stiffening [46]. However, in the present study, our data showed that peroxidase is involved in 'phenylpropanoid biosynthesis' pathways (Figure 6a,b; Figure 7), and the expression pattern was different from that of Almeida [45]. We presume that peroxidase might participate in different metabolic pathways with different expression patterns to regulate somatic embryogenesis in different species. Peroxidase is a phenol oxidase and is highly representative in date palm, and polyphenoloxidase are involved in oxidative browning in date palm [47,48]. Abohatem [49] demonstrates that the low rate of successive transfer culture (every 15 or 20 days) reduced the increase in phenolic contents and peroxidase activities in plant tissue leading to an enhancement of tissues/cells browning and then to a decrease in embryonic cell proliferation. Fresh culture medium every 7 days can significantly reduce the oxidative browning of tissue/cells, which is related to the reduction of phenolic compounds and peroxidase activity, thus increasing the proliferation of embryonic protocells. Based on our proteomic profile results, down regulation of many peroxidase DAPs in PEC versus NEC indicates that peroxidase protein activity is weak during SE, which prevents callus browning and promotes embryogenic differentiation.

\subsubsection{Photosynthesis in Cotton SE}

The photosynthetic potential of cotyledon embryos has been reported in previous studies. For example, in Coffea $\times$ arabusta cotyledons photosynthetic capacity and germinated embryos, the cotyledon embryo stage is the earliest photoautotrophic stage to ensure plant development [50]. Rival [51] reported that the maximum photochemical activity of photosystem II is extremely low in proliferating embryos of oil palm and strongly increases at later developmental stages. In this study, the result is that the expression pattern of DAPs in the 'photosynthetic' pathway is down- to up regulation. According to our results, 'Photosystem I P700 chlorophyll an apoprotein', 'oxygen-evolving enhancer 
protein 2', 'ATP synthase gamma chain' and 'Chlorophyll a-b binding protein' of the 'Photosynthesis' pathway were down regulated in PEC in comparison to GEs (Figure 5b,c; Figure 6a-c). The results indicate that photosynthesis organs and photosynthetic capacity gradually developed from the GE stage for future autotrophy in cotton.

\subsubsection{Response to Environment Stresses during SE of Cotton}

Stresses are the factors that have been increasingly recognized as having important role in the induction of SE [52]. Embryogenic competence of in vitro cultured somatic cells can be stimulated by various factors, such as phytohormone [53,54], dehydration [55,56], explant wounding [57], heavy metal ions $[17,56]$, high osmotic pressure [58,59], etc. Our data showed that a series of stress responsive biological processes were significantly enriched in PEC and GE, including response to acid chemical, water, inorganic substance, oxygen-containing compound, chemical, abiotic stimulus and biotic stimulus, indicating that callus was protected from the external environmental stress through complex regulatory networks to ensure the embryos development of cotton during the PEC-to-embryos transition of cotton (Figure 5c; Figure 8b). Previous studies have shown that decrease of water availability stimulated a shift from proliferation of cells and early embryos to the production of cotyledonary embryos in the developmental program of the culture [60]. In our study, the water content gradually decreased with the callus culture time increased prompted the tissue cells to respond to dry stress and initiate defense mechanisms to ensure embryo development. In the carrot somatic embryogenesis, 2,4-dichlorophenoxyacetic acid (2,4-D) functions as a stress chemical as well as an auxin [61]. During Arabidopsis somatic embryos induction, cells in the shoot apical meristem (SAM) of wild-type seedlings acquired pluripotency or embryogenic potential under initial stress, and then these cells form somatic embryos on 2,4-D treatment [17]. In our culture system, 2,4-D is also used to induce $\mathrm{SE}$, but stress treatment is necessary before exposure to 2,4-D. From the datas above, we can conclude that stress responses are the indispensable biological processes in plant embryos induction.

\subsubsection{Effects of Nitrogen Metabolism Related to SE}

Glutamate dehydrogenase (GDH) is one of the enzymes directly related to nitrogen metabolism. Induction of various GDH isoenzymes may suggest their varied anabolic and catabolic functions [62]. $\mathrm{GDH}$, which is directly involved in the oxidation of amino acids, protect tissues from the toxicity of ammonium [63]. Ganced [64,65] strongly suggested that sugar could control the expression of the GDH gene through catabolic inhibition, which has been described in bacteria and yeast. In this study, GDH in nitrogen metabolism was significantly enriched in GE versus PEC and showed a down regulated trend (Figure $6 \mathrm{a}, \mathrm{c}$ ). We speculate that GDH may be more important during the cotton PEC redifferentiation period.

\subsection{Other DAPs of Regulatory Factors Associated with Cotton SE}

\subsubsection{Phytohormone Response Related Proteins}

Hormones are the most likely candidates in the regulation of developmental switches [16]. Auxin is the main growth regulator in plants, which is involved in the regulation of cell division and differentiation, as well as the existence of other growth regulators such as abscisic acid [66], ethylene [67], gibberellin [68].

In cotton primary embryogenic calli, the DAPs of 'Auxin efflux carrier component' (AP2) and 'indole-3-acetic acid-amido synthetase GH3. 17-like' (GH3) were up regulated (Table 2). Auxin-related proteins are essential for initiating dedifferentiation and cell division in already differentiated cells before they can express embryogenic competence [44]. The PIN gene is believed to be the coding element that regulates the auxin efflux mechanism of the polar auxin transport, which is concluded by the polarity localization of the PIN membrane protein and auxin absorption experiment [69]. Blilou [70] pointed to polar auxin transport as a major factor in organ formation. The GH3 gene is one of several 
sequences screened by differential hybridization of auxin-induced cDNA sequences extracted from auxin-treated soybean tissues [71]. Expression of the GH3 gene has been shown to be rapidly and specifically induced by the application of auxin [72,73]. These conclusions also explained the up regulation of AP2 and GH3 in PEC due to the trend of auxin polar transport organ formation and the key regulation of induced somatic embryo formation.

Gallie [74] identified two ethylene receptor gene families in maize. In developing embryos, the expression levels of members of the two ethylene receptor families were significantly increased, which indicated that embryonic development was involved in ethylene synthesis. In this study, DAPs of 'ethylene receptor-like isoform X1' (Table 2) were involved in the ethylene signaling pathway and were up regulated in PEC compared to NEC, suggesting that ethylene receptor may positively regulate SE initiation in cotton.

In the present study, the differentially accumulated 'GA-stimulated transcript-like protein 1' (GASL1) was down regulated in PEC and GE (Table 2). Ge [11] demonstrated that, at 10 days after GA treatment, 95\% of the embryos showed an aberrant structure, large size, and light-green color. Therefore, we presume that GA negatively affects somatic embryo production and growth via regulation of the GA signaling pathway.

Treatment with ABA improves the efficiency of somatic embryo maturation of Panax ginseng [75] and promotes sugar cane embryo growth [76]. Somatic embryos treated with ABA generate the highest yield of plantlets in Picea abies [77]. In our results, the 'abscisic acid receptor PYR1-like' DAP, which is involved in the ABA signal pathway, was up regulated in GE compared to PEC (Table 2); this suggests that the 'abscisic acid receptor PYR1-like protein' promotes embryo maturation in GE.

\subsubsection{Signal Transduction Related Proteins}

In this study, we also found that a large number of important signal regulators, including kinases, calcium signals and GTP-binding related proteins (Table 2), were significantly differential expressed in cotton SE. $\mathrm{Ca}^{2+}$ has an important role in the establishment of cellular polarity during embryogenesis in plants [78]. It as a secondary messenger may trigger various signal transduction pathways [79] in plants SE. Calmodulin or $\mathrm{Ca}^{2+}$-dependent protein kinase may be involved in the regulation of $\mathrm{Ca}^{2+}$ levels in the proembryogenic cell mass (PEM) of sandalwood to promote embryo development [80]. In our TMT profile, the calcium-related proteins 'calcium-dependent protein kinase 11-like' and 'probable calcium-binding protein CML27' were simultaneously up regulated in PEC versus NEC. We presume that calcium-related proteins involved in signal transduction and regulation of calcium balance, thereby establishing polarity to promote cotton SE.

Phosphoenolpyruvate carboxylase (PEPC), a glycolytic protein and $\mathrm{CO}_{2}$-fixing enzyme [81], participates in TCA cycle under non-photosynthesis conditions [82] and signal transduction of plant embryo development [83]. Therefore, this metabolic pathway maintains the carbon residue pool necessary for oil and storage protein biosynthesis that occurred the later in embryonic development [84]. In our study, the protein 'phosphoenolpyruvate carboxykinase [ATP]-like' was up regulated in PEC versus NEC and down regulated in GE versus PEC (Table 2). Thus, we presume that PEPC may not only participate in TCA cycle and fixation of $\mathrm{CO}_{2}$ but also in signal transduction in PEC, providing energy for cotton SE transformation process.

As a result, calcium-related proteins, PEPC and other signal transduction proteins may be involved in a variety of biological processes to promote the transformation process of cotton SE.

\subsubsection{SE Associated Proteins of Aquaporins and Fatty Acid Metabolism}

In our TMT profile, a large number of aquaporins, including PIP and TIPs, were found to be significantly involved in PEC and GE initiation during SE. Aquaporin was involved in water transport by osmosis to prevent dryness and abortion during embryonic development, which was of great significance in the development of Picea asperata somatic embryos [85]. Here, we found that the aquaporins (PIP210, TIP14 and PIP type) were significantly down regulated during PEC; the 
aquaporins (PIP2-5, TIP3-2) were significantly up regulated during GE (Table 2). Therefore, we suspect that these proteins are sensitive to water content and light induction during cotton SE initiation process of transdifferentiation. Similarly, previous studies have shown that aquaporin, under stress conditions, forms a 'tunnel' to regulate the water transport in the cell membrane [86], and can be induced by light [87]. In addition to reducing the activation energy of water transport, aquaporin also enhanced the permeability of the plasma membrane [88].

Many fatty acid biosynthesis- and metabolism-related proteins, such as 'cytochrome P450 86B1-like' and 'cytochrome P450 86A8-like', were differentially accumulated. In the fatty acid biosynthesis pathway, they were up regulated in PEC (Table 2). A previous study reported that fatty acids, which affect cell function and growth patterns, appear to be a part of the TDZ action pattern and may play an important role in inducing regeneration [89]. These results implied that aquaporins and perturbations of fatty acid metabolism contribute to the initiation of SE in cotton.

\subsubsection{Regulation of SE-related Proteins, Transcription, Posttranscription and Modification}

In this study, two types of SE-related proteins and multiple types of transcription factors, zinc finger domains, microRNAs and modification-related proteins were identified (Table 2). Late embryogenesis abundant protein (LEA) was first found in cotton (Gossypium hirsutum) seeds and accumulated in the late stages of embryogenesis, which played a crucial role in cell dehydration tolerance [90]. In current study, two types of SE-related proteins, 'embryonic protein DC-8-like' and 'embryogenesis abundant protein', were up regulated in GE. It indicating that they may positively regulate somatic embryo maturation and involve in cell dehydration tolerance in cotton.

WUSCHEL (WUS) is a vital transcription factor for labeling embryonic cells [24]. The capability of promoting the vegetative to embryonic transition by WUS, and eventually forming somatic embryos, suggesting that the homeodomain protein also plays a critical role during embryogenesis, in addition to its function in meristem development [91]. In this result, 'WUSCHEL-related homeobox 9-like' was up regulated in PEC, indicating that the WUSCHEL-related protein is essential for the initiation of somatic embryogenesis. In addition to WUS, we also found other transcription factors, zinc finger domains related to SE (Table 2).

Members of the Argonaute protein family are key players in the small RNA-directed gene silencing pathway. Various types of small RNA and Argonaute proteins played important roles in embryonic development, cell differentiation and transposon silencing in all higher eukaryotes [92].

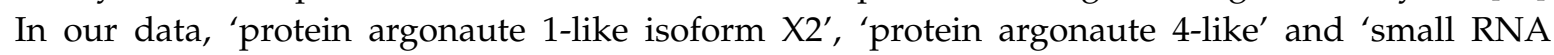
2'-O-methyltransferase-like isoform $X 4^{\prime}$ ' were significantly up regulated during PEC versus NEC (Table 2), suggesting that RNA-mediated post-transcriptional regulation played an important role in the process of cotton SE transformation as reported in other plants [93-95].

In current study, we identified several types of modification-related DAPs, including DNA methylation, chromatin modification, acetylation, ubiquitination and phosphorylation. In the process of carrot SE, the removal of auxin led to the loss of DNA methylation, so that the embryo continued to develop [96]. Six types of methylation-related proteins were identified, which dynamically regulated to cotton SE by different expression patterns. Efficient modification of chromatin structure was crucial in the epigenetic regulation of genes [97]. In our data, 'chromatin modification-related protein MEAF6-like isoform X3' promoted maturation and development of cotton GEs by epigenetic regulation. In addition, during the PEC period, we also identified acetylation, ubiquitination and phosphorylation-related proteins with different expression patterns (Table 2), indicating that they played diverse and indispensable functions in regulating cotton SE.

The different expression patterns of SE-related proteins, multitudinal transcription, posttranscription and modification showed that they played a pivotal role in the process of cotton SE [98-103]. The results of our high-through put proteomics assay, the large scale of proteins associated with SE, and their complex expression patterns suggest that SE is a concerted process involving multiple molecular pathways controlled by a complicated gene regulatory network. 


\section{Materials and Methods}

\subsection{Plant Materials and Culture Conditions}

Seeds of cotton cultivar Yuzao 1 (Institute of Cotton Research of CAAS), uncovering the coats, were imbibed in $0.1 \%(w / v) \mathrm{HgCl}_{2}$ for $10 \mathrm{~min}$, then rinsed four times by sterile distilled water and germinated on Murashige and Skoog (MS) medium containing 3\% $(w / v)$ sucrose and $0.3 \%(w / v)$ Phytegel. Hypocotyl explants $(0.5-1.0 \mathrm{~cm})$ taken from 5-7 d old seedlings and non-embryogenic callus initiation of Yuzao 1 was done, as described by Wu [104], in MS medium plus B5 vitamins medium (MSB) containing $0.46 \mu \mathrm{mol} \mathrm{L}-1$ kinetin and $0.45 \mu \mathrm{mol} \mathrm{L}-1$ 2,4-D. Calli were subcultured in MSB medium without any hormone to induce embryogenic calli (EC), as described by Zeng [39]. Samples were collected from the following three stages of SEM (1) NEC from explants cultured in MSB, induced (2) PEC and (3) GEs. The collected samples were immediately frozen in liquid nitrogen, and stored at $-80^{\circ} \mathrm{C}$ before protein extraction. Each staged sample was prepared for three biological replicates.

\subsection{Protein Extraction and Identification}

\subsubsection{Protein Samples Preparation}

The three biological replicates of sample were first ground by liquid nitrogen, then the powder was transferred to $5 \mathrm{~cm}^{3}$ centrifuge tube and sonicated three times on ice using a high intensity ultrasonic processor (Scientz, Ningbo, China) in 4-fold volume phenol extraction buffer (including $10 \mathrm{mM}$ dithiothreitol, $1 \%$ Protease Inhibitor Cocktail and $2 \mathrm{mM}$ EDTA). The equal amount of trisaturated phenol ( $\mathrm{pH}$ 8.0) was added; then, the mixture was further vortexed for $5 \mathrm{~min}$. After centrifugation $\left(4^{\circ} \mathrm{C}\right.$, $10 \mathrm{~min}, 5000 \times \mathrm{g}$ ), the upper stage of phenol was transferred to a new centrifuge tube. Proteins were precipitated by adding at five volume of $0.1 \mathrm{M}$ ammonium sulfate-saturated methanol to precipitate overnight. After centrifugation at $4{ }^{\circ} \mathrm{C}$ for $10 \mathrm{~min}$, the supernatant was discarded. The remaining precipitate was washed with ice-cold methanol once, followed by ice-cold acetone for three times. The protein was redissolved in $8 \mathrm{M}$ urea and the protein concentration was determined with BCA kit (Beyotime Biotechnology, Shanghai, China) according to the manufacturer's instructions.

\subsubsection{Trypsin Digestion}

Protein solution with dithiothreitol makes its final concentration of $5 \mathrm{mM}, 56^{\circ} \mathrm{C}$ for $30 \mathrm{~min}$. After that, acetamide was added to make the final concentration $11 \mathrm{mM}$ and incubated in the dark at room temperature for $15 \mathrm{~min}$. Finally, the sample urea concentration was diluted to less than $2 \mathrm{M}$. With 1:50 $(w / w)$ quality ratio (trypsin: protein) to join the pancreatic enzyme, $37^{\circ} \mathrm{C}$ enzyme solution for the night. Then the trypsin (Promega, Madison, WI, USA) was added at a mass ratio of 1:100 (trypsin: protein), and the enzymatic hydrolysis continued for $4 \mathrm{~h}$.

\subsubsection{TMT Labeling}

After trypsin digestion, the peptide was desalted by Strata X C18 SPE column (Phenomenex, Torrance, CA, USA) and vacuum-dried. The peptide was reconstituted in 0.5 M TEAB (Sigma, St. Louis, MI, USA) and processed according to the manufacturer's protocol for TMT kit (Thermo Fisher Scientific, Waltham, MA, USA). Briefly, one unit of TMT reagent was thawed and reconstituted in acetonitrile. The peptide mixtures were then incubated for $2 \mathrm{~h}$ at room temperature and pooled, desalted and dried by vacuum centrifugation.

\subsubsection{HPLC Fractionation and LC-MS/MS Analysis}

The tryptic peptides were fractionated into fractions by high $\mathrm{pH}$ reverse-phase HPLC using Agilent 300Extend C18 column ( $5 \mu \mathrm{m}$ particles, $4.6 \mathrm{~mm}$ ID, $250 \mathrm{~mm}$ length, Agilent, Santa Clara, USA). Briefly, peptides were first separated with a gradient of $8 \%$ to $32 \%$ acetonitrile (pH 9.0) over 60 min into 60 fractions. Then, the peptides were combined into 9 fractions and dried by vacuum centrifuging. 
The tryptic peptides were dissolved in $0.1 \%$ formic acid (solvent A), directly loaded onto a home-made reversed-phase analytical column (15-cm length, $75 \mu \mathrm{m}$ i.d.). The gradient was comprised of an increase from $8 \%$ to $23 \%$ solvent B ( $0.1 \%$ formic acid in $90 \%$ acetonitrile) over $38 \mathrm{~min}, 23 \%$ to $35 \%$ in $14 \mathrm{~min}$ and climbing to $80 \%$ in $4 \mathrm{~min}$ then holding at $80 \%$ for the last $4 \mathrm{~min}$, all at a constant flow rate of $450 \mathrm{~nL} / \mathrm{min}$ on an EASY-nLC 1000 UPLC system (Thermo Fisher Scientific, Waltham, MA, USA).

The peptides were subjected to NSI source followed by tandem mass spectrometry (MS/MS) in Q Exactive ${ }^{\mathrm{TM}}$ HF-X (Thermo Fisher Scientific, Waltham, MA, USA) coupled online to the UPLC. The electrospray voltage applied was $2.0 \mathrm{kV}$. The $\mathrm{m} / \mathrm{z}$ scan range was 350-1600 $\mathrm{m} / \mathrm{z}$ for a full scan, and intact peptides were detected in the Orbitrap (Thermo Fisher Scientific, Waltham, MA, USA) at a resolution of 60,000. Peptides were then selected for MS/MS using NCE setting as 28 and the fragments were detected in the Orbitrap at a resolution of 17,500. A data-dependent procedure that alternated between one MS scan followed by 20 MS/MS scans with $30 \mathrm{~s}$ dynamic exclusion. Automatic gain control (AGC) was set at 1E5. The fixed first mass was set as $100 \mathrm{~m} / z$. The HPLC Fractionation and LC-MS/MS Analysis in our research is supported by Jingjie PTM BioLabs (Hangzhou, China).

\subsubsection{Database Search}

The resulting MS/MS data were processed using Maxquant search engine (v.1.5.2.8). Tandem mass spectra were searched against the UniProt 14.1 (2009)—Gossypium hirsutum database (78,387 sequences) concatenated with reverse decoy database. Trypsin/P was specified as cleavage enzyme allowing up to 2 missing cleavages. The first search was $20 \mathrm{ppm}$, the main search was $5 \mathrm{ppm}$, and the fragment ion mass tolerance was $0.02 \mathrm{Da}$.

\subsection{Bioinformatics}

\subsubsection{Annotation Methods}

GO Annotation

Gene Ontology (GO) annotation proteome was derived from the UniProt-GOA database (http://www.ebi.ac.uk/GOA/). Firstly, converting identified protein ID to UniProt ID and then mapping to GO IDs by protein ID. If some identified proteins were not annotated by UniProt-GOA database, the InterProScan soft would be used to annotated protein's GO functional based on protein sequence alignment method. Then proteins were annotated according to the biological process, cellular component and molecular function of the three categories of protein Gene Ontology annotation.

\section{Domain Annotation}

Identified proteins domain functional description were annotated by InterProScan (a sequence analysis application) based on protein sequence alignment method, and the InterPro domain database was used. InterPro (http:/ / www.ebi.ac.uk/interpro/) is a database that integrates diverse information about protein families, domains and functional sites, and makes it freely available to the public via Web-based interfaces and services. At the heart of the database are diagnostic models, known as signatures, from which protein sequences can be searched for potential functions. InterPro has applications in large-scale genome-wide and metagenomic analyses, and the characterization of individual protein sequences.

\section{KEGG Pathway Annotation}

KEGG connects known information on molecular interaction networks, such as pathways and complexes (the "Pathway" database), information about genes and proteins generated by genome projects (including the gene database) and information about biochemical compounds and reactions (including compound and reaction databases). These databases are different networks, known as the "protein network", respectively, and the "chemical universe", respectively. Efforts 
are being made to increase KEGG knowledge, including information on orthographic clustering in the KEGG orthographic database. KEGG Pathways mainly including: Metabolism, Genetic Information Processing, Environmental Information Processing, Cellular Processes, Rat Diseases, Drug Development. Kyoto Encyclopedia of Genes and Genomes (KEGG) database (http:/ / www.genome. $\mathrm{jp} / \mathrm{kegg} /$ ) was used to annotate protein pathway. Firstly, using KEGG online service tools KAAS (http://www.genome.jp/kaas-bin/kaas_main) to annotate protein's KEGG database description. Then mapping the annotation result on the KEGG pathway database using KEGG online service tools KEGG mapper (http:/ / www.kegg.jp/kegg/mapper.html).

Subcellular Localization Prediction

Eukaryotic cells are elaborately subdivided into membrane-bound chambers with unique functions. Some major constituents of eukaryotic cells are extracellular space, cytoplasm, nucleus, mitochondria, Golgi apparatus, endoplasmic reticulum (ER), peroxisome, vacuoles, cytoskeleton, nucleoplasm, nucleolus, nuclear matrix, and ribosomes. There, we used wolfpsort (http:// www.genscript.com/psort/wolf_psort.html) a subcellular localization predication soft to predict subcellular localization. Wolfpsort is an updated version of PSORT/PSORT II for the prediction of eukaryotic sequences.

\subsubsection{Functional Enrichment}

\section{Enrichment of Gene Ontology Analysis}

Through GO annotation, proteins are divided into biological process, cellular compartment, and molecular function. For each class, we used a double-tailed Fisher's precision test to detect the enrichment of differentially abundant proteins relative to all identified proteins. GO with a revised $p$ value of $<0.05$ is considered significant.

Enrichment of Pathway Analysis

KEGG database identified enrichment pathways by double-tailed Fisher's precision test to detect the enrichment of differentially abundant proteins against all identified proteins. The pathway with a corrected $p$-value $<0.05$ was considered significant. According to the KEGG website, these paths are classified into hierarchical categories.

\section{Enrichment of Protein Domain Analysis}

For each category protein, InterPro (a resource that provides a functional analysis of protein sequences by classifying them into families and predicting the presence of domains and important sites) database was researched and a two-tailed Fisher's exact test was employed to test the enrichment of the differentially abundant proteins against all identified proteins. Protein domains with a $p$-value $<$ 0.05 were considered significant.

\section{Enrichment-Based Clustering}

For further hierarchical clustering based on different protein functional classification (such as GO, Domain, Pathway, Complex). We first collated all the categories obtained after enrichment along with their $p$ values, and then filtered for those categories which were at least enriched in one of the clusters with $p$ value $<0.05$. This filtered $P$ value matrix was transformed by the function $x=-\log 10$ ( $p$ value). Finally, these $\mathrm{x}$ values were $\mathrm{z}$-transformed for each functional category. These $\mathrm{z}$ scores were then clustered by one-way hierarchical clustering (Euclidean distance, average linkage clustering) in Genesis. Cluster membership was visualized by a heat map using the "heatmap.2" function from the "gplots" R-package. 
Supplementary Materials: Supplementary materials can be found at http:/ /www.mdpi.com/1422-0067/20/7/ 1691/s1.

Author Contributions: Data curation, H.G. (Haixia Guo), H.G. (Huihui Guo), L.Z., Y.F. (Yijie Fan), Y.F. (Yupeng Fan) and Z.T.; Formal analysis, H.G. (Haixia Guo), H.G. (Huihui Guo), Z.T. and F.Z.; Funding acquisition, F.Z.; Investigation, H.G. (Haixia Guo), H.G. (Huihui Guo), L.Z., Y.F. (Yijie Fan) and Y.F. (Yupeng Fan); Methodology, Z.T.; Project administration, F.Z.; Resources, H.G. (Haixia Guo), H.G. (Huihui Guo), L.Z., Y.F. (Yijie Fan) and Y.F. (Yupeng Fan); Supervision, F.Z.; Writing-original draft, H.G. (Haixia Guo), H.G. (Huihui Guo) and L.Z.; Writing-review \& editing, H.G. (Haixia Guo) and F.Z.

Funding: This work was supported by National Key Research and Development Program (2018YFD0100303; 2016YFD0100306), Taishan Scholar Talent Project from PRC (TSQN20161018), the National Natural Science Foundation of China (31401428) and Fok Ying-Tong Foundation (151024).

Acknowledgments: We are grateful for the technique support provided by Jingjie Biotechnology Co., Ltd., Hangzhou, China.

Conflicts of Interest: The authors declare no conflict of interest.

$\begin{array}{ll}\text { Abbreviations } \\ \text { ABA } & \text { Abscisic acid } \\ \text { DAPs } & \text { Differentially accumulated proteins } \\ \text { EC } & \text { Embryogenic calli } \\ \text { GA } & \text { Gibberellin } \\ \text { GEs } & \text { Globular embryos } \\ \text { GO } & \text { Gene Ontology } \\ \text { iTRAQ } & \text { Isobaric tags for relative and absolute quantitation } \\ \text { KEGG } & \text { Kyoto encyclopedia of genes and genomes } \\ \text { MS } & \text { Murashige and Skoog } \\ \text { MSB } & \text { Vitamins medium } \\ \text { NEC } & \text { Nonembryogenic calli } \\ \text { PEC } & \text { Primary embryogenic calli } \\ \text { PEM } & \text { Proembryogenic cell mass } \\ \text { SE } & \text { Somatic embryogenesis } \\ \text { SEM } & \text { Somatic embryogenesis masses } \\ \text { SSH } & \text { Suppression subtractive hybridization } \\ \text { TMT } & \text { The isobaric labels tandem mass tags }\end{array}$

\section{References}

1. Wilkins, T.A.; Rajasekaran, K.; Anderson, D.M. Cotton biotechnology. Crit. Rev. Plant Sci. 2000, 19, 511-550. [CrossRef]

2. Brookes, G.; Barfoot, P. GM Crops: Global Socio-Economic and Environmental Impacts 1996-2010; PG Economics, Ltd.: Dorchester, UK, 2012; Available online: http:/ / www.pgeconomics.co.uk/page/33/global-impact-2012 (accessed on 13 January 2013).

3. Zhao, X.Y.; Su, Y.H.; Cheng, Z.J.; Zang, X.S. Cell fate switch during in vitro plant organogenesis. J. Integr. Plant Biol. 2008, 50, 816-824. [CrossRef] [PubMed]

4. Mujib, A. Somatic Embryogenesis in Ornamentals and Its Applications; Springer: New Delhi, India, 2016; pp. 67-86.

5. Fehér, A. The initiation phase of somatic embryogenesis: What we know and what we don't. Acta Biol. Szeged. 2008, 52, 53-56.

6. Fehér, A. Somatic embryogenesis-stress-induced remodeling of plant cell fate. BBA-Gene Regul. Mech. 2015, $1849,385-402$.

7. Stewards, F.C.; Mapbs, M.O.; Mears, K. Growth and organized development of cultured cells I. Organization in cultures grown from freely suspended cells. Am. J. Bot. 1958, 45, 705-708. [CrossRef]

8. Rao, A.Q.; Hussain, S.S.; Shahzad, M.S.; Bokhari, S.Y.; Raza, M.H.; Rakha, A.; Majeed, A.; Shahid, A.A.; Saleem, Z.; Husnain, T.; Riazuddin, S. Somatic embryogenesis in wild relatives of cotton (Gossypium Spp.). J. Zhejiang Univ. Sci. B 2006, 7, 291-298. [CrossRef] [PubMed] 
9. Evans, D.A.; Sharp, W.R.; Flick, C.E. Growth and Behavior of Cell Cultures: Embryogenesis and Organogenesis. Plant Tissue Cultures; Trevor, A.T., Ed.; Academic Press: New York, NY, USA, 1981; pp. 45-113.

10. Scowcroft, W.R. Genetic Variability in Tissue Culture: Impact on Germplasm Conservation and Utilization; IBPGR: Roma, Italy, 1984; p. 41. Available online: http:/ /www.sidalc.net/cgi-bin/wxis.exe/?IsisScript=bac.xis\& method=post\&formato $=2 \&$ cantidad $=1 \&$ expresion $=\mathrm{mfn}=048729$ (accessed on 3 April 2019).

11. Ge, X.; Zhang, C.; Wang, Q.; Yang, Z.; Wang, Y.; Zhang, X.; Wu, Z.; Hou, Y.; Wu, J.; Li, F. iTRAQ protein profile differential analysis between somatic globular and cotyledonary embryos reveals stress, hormone, and respiration involved in increasing plantlet regeneration of Gossypium hirsutum L. J. Proteome Res. 2014, 14, 268-278. [CrossRef] [PubMed]

12. Sakhanokho, H.F.; Rajasekaran, K. Cotton regeneration in vitro. In Fiber Plants; Ramawat, K.G., Ed.; Springer: Cham, Switzerland, 2016; pp. 87-110.

13. Fehér, A. Why somatic plant cells start to form embryos? In Somatic Embryogenesis; Mujib, A., Ed.; Springer: Berlin/Heidelberg, Germany, 2005; pp. 85-101.

14. Karami, O.; Aghavaisi, B.; Pour, A.M. Molecular aspects of somatic-to-embryogenic transition in plants. J. Chem. Biol. 2009, 2, 177-190. [CrossRef] [PubMed]

15. Elhiti, M.; Stasolla, C.; Wang, A. Molecular regulation of plant somatic embryogenesis. In Vitro Cell. Dev. Biol. Plant 2013, 49, 631-642. [CrossRef]

16. Fehér, A.; Pasternak, T.P.; Dudits, D. Transition of somatic plant cells to an embryogenic state. Plant Cell Tissue Org. 2003, 74, 201-228. [CrossRef]

17. Ikeda-Iwai, M.; Umehara, M.; Satoh, S.; Kamada, H. Stress-induced somatic embryogenesis in vegetative tissues of Arabidopsis thaliana. Plant J. 2003, 34, 107-114. [CrossRef] [PubMed]

18. Rose, R.J.; Nolan, K.E. Invited review: Genetic regulation of somatic embryogenesis with particular reference to Arabidopsis thaliana and Medicago truncatula. In Vitro Cell. Dev. Biol. Plant 2006, 42, 473-481. [CrossRef]

19. Reinert, J. Über die Kontrolle der Morphogenese und die Induktion von Adventivembryonen an Gewebekulturen aus Karotten. Planta 1959, 53, 318-333. [CrossRef]

20. Quiroz-Figueroa, F.R.; Rojas-Herrera, R.; Galaz-Avalos, R.M.; Loyola-Vargas, V.M. Embryo production through somatic embryogenesis can be used to study cell differentiation in plants. Plant Cell Tissue Org. 2006, 86, 285. [CrossRef]

21. Mathieu, M.; Lelu-Walter, M.A.; Blervacq, A.S.; David, H.; Hawkins, S.; Neutelings, G. Germin-like genes are expressed during somatic embryogenesis and early development of conifers. Plant Mol. Biol. 2006, 61, 615-627. [CrossRef] [PubMed]

22. Thorpe, T.A. In Vitro Embryogenesis in Plants. Springer Science \& Business Media: Dordrecht, The Netherlands, 1995; pp. 267-308.

23. Lakshmanan, P.; Taji, A. Somatic embryogenesis in leguminous plants. Plant Biol. 2000, 2, 136-148. [CrossRef]

24. Elhiti, M.; Tahir, M.; Gulden, R.H.; Khamiss, K.; Stasolla, C. Modulation of embryo-forming capacity in culture through the expression of Brassica genes involved in the regulation of the shoot apical meristem. J. Exp. Bot. 2010, 61, 4069-4085. [CrossRef] [PubMed]

25. Zuo, J.; Niu, Q.W.; Frugis, G.; Chua, N. The WUSCHEL gene promotes vegetative-to-embryonic transition in Arabidopsis. Plant J. 2002, 30, 349-359. [CrossRef]

26. Weijers, D.; Sauer, M.; Meurette, O.; Friml, J.; Ljung, K.; Sandberg, G.; Hooykaas, P.; Offringa, R. Maintenance of embryonic auxin distribution for apical-basal patterning by PIN-FORMED-dependent auxin transport in Arabidopsis. Plant Cell 2005, 17, 2517-2526. [CrossRef]

27. Su, Y.H.; Zhao, X.Y.; Liu, Y.B.; Zhang, C.L.; O’Neill, S.D.; Zhang, X.S. Auxin-induced WUS expression is essential for embryonic stem cell renewal during somatic embryogenesis in Arabidopsis. Plant J. 2009, 59, 448-460. [CrossRef]

28. Vogler, H.; Kuhlemeier, C. Simple hormones but complex signalling. Curr. Opin. Plant Biol. 2003, 6, 51-56. [CrossRef]

29. Braybrook, S.A.; Harada, J.J. LECs go crazy in embryo development. Trends Plant Sci. 2008, 13, 624-630. [CrossRef] [PubMed]

30. Giraudat, J.; Parcy, F.; Bertauche, N.; Gosti, F.; Leung, J.; Morris, P.C.; Bouvier-Durand, M.; Vartanian, N. Current advances in abscisic acid action and signalling. In Signals and Signal Transduction Pathways in Plants; Palme, K., Ed.; Springer: Dordrecht, The Netherlands, 1994; pp. 321-341. 
31. Ton, J.; Mauch-Mani, B. $\beta$-amino-butyric acid-induced resistance against necrotrophic pathogens is based on ABA-dependent priming for callose. Plant J. 2004, 38, 119-130. [CrossRef] [PubMed]

32. Letarte, J.; Simion, E.; Miner, M.; Kasha, K.J. Arabinogalactans and arabinogalactan-proteins induce embryogenesis in wheat (Triticum aestivum L.) microspore culture. Plant Cell 2006, 24, 691. [CrossRef] [PubMed]

33. Singla, B.; Tyagi, A.K.; Khurana, J.P.; Khurana, P. Analysis of expression profile of selected genes expressed during auxin-induced somatic embryogenesis in leaf base system of wheat (Triticum aestivum) and their possible interactions. Plant Mol. Biol. 2007, 65, 677-692. [CrossRef] [PubMed]

34. Mantiri, F.R.; Kurdyukov, S.; Lohar, D.P.; Sharopova, N.; Saeed, N.A.; Wang, X.D.; Vandenbosch, K.A.; Rose, R.J. The transcription factor MtSERF1 of the ERF subfamily identified by transcriptional profiling is required for somatic embryogenesis induced by auxin plus cytokinin in Medicago truncatula. Plant Physiol. 2008, 146, 1622-1636. [CrossRef] [PubMed]

35. Kulinska-Lukaszek, K.; Tobojka, M.; Adamiok, A.; Kurczynska, E.U. Expression of the BBM gene during somatic embryogenesis of Arabidopsis thaliana. Biol. Plant. 2012, 56, 389-394. [CrossRef]

36. Yang, Z.; Li, C.; Wang, Y.; Zhang, C.; Wu, Z.; Zhang, X.; Liu, C.; Li, F. GhAGL15s, preferentially expressed during somatic embryogenesis, promote embryogenic callus formation in cotton (Gossypium hirsutum L.). Mol. Genet. Genom. 2014, 289, 873-883. [CrossRef]

37. Zheng, Q.; Zheng, Y.; Perry, S.E. AGAMOUS-Like15 Promotes Somatic Embryogenesis in Arabidopsis thaliana and Glycine max in Part by Control of Ethylene Biosynthesis and Response. Plant Physiol. 2013, 161, 2113-2127. [CrossRef]

38. Schmidt, E.D.; Guzzo, F.; Toonen, M.A.; de Vries, S.C. A leucine-rich repeat containing receptor-like kinase marks somatic plant cells competent to form embryos. Development 1997, 124, 2049-2062.

39. Zeng, F.; Zhang, X.; Zhu, L.; Tu, L.; Guo, X.; Nie, Y. Isolation and characterization of genes associated to cotton somatic embryogenesis by suppression subtractive hybridization and macroarray. Plant Mol. Biol. 2006, 60, 167-183. [CrossRef] [PubMed]

40. Thompson, A.; Schäfer, J.; Kuhn, K.; Kienle, S.; Schwarz, J.; Schmidt, G.; Neumann, T.; Johnstone, R.; Mohammed, A.K.; Hamon, C. Tandem mass tags: A novel quantification strategy for comparative analysis of complex protein mixtures by MS/MS. Anal. Chem. 2003, 75, 1895-1904. [CrossRef] [PubMed]

41. Pagel, O.; Loroch, S.; Sickmann, A.; Zahedi, R.P. Current strategies and findings in clinically relevant post-translational modification-specific proteomics. Expert Rev. Proteom. 2015, 12, 235-253. [CrossRef] [PubMed]

42. Klubicová, K.; Uvácková, L.; Danchenko, M.; Nemecek, P.; Skultéty, L.; Salaj, J.; Salaj, T. Insights into the early stage of Pinus nigra Arn. somatic embryogenesis using discovery proteomics. J. Proteom. 2017, 169, 99-111. [CrossRef] [PubMed]

43. Sghaier-Hammami, B.; Drira, N.; Jorrín-Novo, J.V. Comparative 2-DE proteomic analysis of date palm (Phoenix dactylifera L.) somatic and zygotic embryos. J. Proteom. 2009, 73, 161-177. [CrossRef] [PubMed]

44. Zhu, H.G.; Cheng, W.H.; Tian, W.G.; Li, Y.J.; Liu, F.; Xue, F.; Zhu, Q.H.; Sun, Y.Q.; Sun, J. iTRAQ-based comparative proteomic analysis provides insights into somatic embryogenesis in Gossypium hirsutum L. Plant Mol. Biol. 2018, 96, 89-102. [CrossRef] [PubMed]

45. Almeida, A.M.; Parreira, J.R.; Santos, R.; Duque, A.S.; Francisco, R.; Tomé, D.F.; Ricardo, C.P.; Coelho, A.V.; Fevereiro, P. A proteomics study of the induction of somatic embryogenesis in Medicago truncatula using 2DE and MALDI-TOF/TOF. Physiol. Plant. 2012, 146, 236-249. [CrossRef]

46. Passardi, F.; Theiler, G.; Zamocky, M.; Cosioa, C.; Rouhier, N.; Teixera, F.; Margis-Pinheiroe, M.; Ioannidis, V.; Penel, C.; Falquet, L.; Dunand, C. PeroxiBase: The peroxidase database. Phytochemistry 2007, 68, 1605-1611. [CrossRef]

47. Baaziz, M.; Saaidi, M. Preliminary identification of date palm cultivars by esterase isoenzymes and peroxidase activities. Can. J. Bot. 1988, 66, 89-93. [CrossRef]

48. Baaziz, M. The activity and preliminary characterization of peroxidases in leaves of cultivars of date palm, Phoenix dactylifera L. New Phytol. 1989, 111, 403-411. [CrossRef]

49. Abohatem, M.; Zouine, J.; El Hadrami, I. Low concentrations of BAP and high rate of subcultures improve the establishment and multiplication of somatic embryos in date palm suspension cultures by limiting oxidative browning associated with high levels of total phenols and peroxidase activities. Sci. Hortic. Amst. 2011, 130, 344-348. [CrossRef] 
50. Afreen, F.; Zobayed, S.M.A.; Kozai, T. Photoautotrophic culture of Coffea arabusta somatic embryos: Photosynthetic ability and growth of different stage embryos. Ann. Bot. 2002, 90, 11-19. [CrossRef] [PubMed]

51. Rival, A.; Beulé, T.; Lavergne, D.; Nato, A.; Havaux, M.; Puard, M. Development of photosynthetic characteristics in oil palm during in vitro micropropagation. J. Plant Physiol. 1997, 150, 520-527. [CrossRef]

52. Karami, O.; Saidi, A. The molecular basis for stress-induced acquisition of somatic embryogenesis. Mol. Biol. Rep. 2010, 37, 2493-2507. [CrossRef] [PubMed]

53. Cui, K.; Xing, G.; Zhou, G.; Liu, X.; Wang, Y. The induced and regulatory effects of plant hormones in somatic embryogenesis. Hereditas 2000, 22, 349-354.

54. Jiménez, V.M. Regulation of in vitro somatic embryogenesis with emphasis on to the role of endogenous hormones. Rev. Bras. Fisiol. Veg. 2001, 13, 196-223. [CrossRef]

55. Kumria, R.; Sunnichan, V.G.; Das, D.K.; Gupta, S.K.; Reddy, V.S.; Bhatnagar, R.K.; Leelavathi, S. High-frequency somatic embryo production and maturation into normal plants in cotton (Gossypium hirsutum) through metabolic stress. Plant Cell Rep. 2003, 21, 635-639. [PubMed]

56. Patnaik, D.; Mahalakshmi, A.; Khurana, P. Effect of water stress and heavy metals on induction of somatic embryogenesis in wheat leaf base cultures. Indian J. Exp. Biol. 2005, 43, 740-745. [PubMed]

57. Cheong, Y.H.; Chang, H.S.; Gupta, R.; Wang, X.; Zhu, T.; Luan, S. Transcriptional profiling reveals novel interactions between wounding, pathogen, abiotic stress, and hormonal responses in Arabidopsis. Plant Physiol. 2002, 129, 661-677. [CrossRef]

58. Karami, O.; Deljou, A.; Esna-Ashari, M.; Ostad-Ahmadi, P. Effect of sucrose concentrations on somatic embryogenesis in carnation (Dianthus caryophyllus L.). Sci. Hortic. 2006, 110, 340-344. [CrossRef]

59. Karami, O.; Deljou, A.; Kordestani, G.K. Secondary somatic embryogenesis of carnation (Dianthus caryophyllus L.). Plant Cell 2008, 92, 273-280. [CrossRef]

60. Klimaszewska, K.; Cyr, D.R.; Sutton, B.C.S. Influence of gelling agents on culture medium gel strength, water availability, tissue water potential, and maturation response in embryogenic cultures of Pinus strobus L. In Vitro Cell Dev. Biol. Plant 2000, 36, 279-286. [CrossRef]

61. Kiyosue, T. Somatic embryogenesis in higher plants. J. Plant Res. 1993, 3, 75-82.

62. Lehmann, T.; Polcyn, W.; Ratajczak, L. Glutamate dehydrogenase isoenzymes in yellow lupine root nodules. III. Affinity for ammonia. Acta Physiol. Plant 1990, 12, 259-263.

63. Yamaya, T.; Oaks, A. Synthesis of glutamate by mitochondria-an anaplerotic function for glutamate dehydrogenase. Physiol. Plant. 1987, 70, 749-756. [CrossRef]

64. Gancedo, J.M. Yeast carbon catabolite repression. Microbiol. Mol. Biol. R. 1998, 62, 334-361.

65. Saier, M.H. Protein phosphorylation and allosteric control of inducer exclusion and catabolite repression by the bacterial phosphoenolpyruvate: Sugar phosphotransferase system. Microbiol. Mol. Biol. Rev. 1989, 53, 109-120.

66. Nishiwaki, M.; Fujino, K.; Koda, Y.; Masuda, K.; Kikuta, Y. Somatic embryogenesis induced by the simple application of abscisic acid to carrot (Daucus carota L.) seedlings in culture. Planta 2000, 211, 756-759. [CrossRef]

67. Jin, L.G.; Li, H.; Liu, J.Y. Molecular characterization of three ethylene responsive element binding factor genes from cotton. J. Integr. Plant Biol. 2010, 52, 485-495. [CrossRef]

68. Ho, S.L.; Huang, L.F.; Lu, C.A.; He, S.L.; Wang, C.C.; Yu, S.P.; Chen, J.; Yu, S.M. Sugar starvation-and GA-inducible calcium-dependent protein kinase 1 feedback regulates GA biosynthesis and activates a 14-3-3 protein to confer drought tolerance in rice seedlings. Plant Mol. Biol. 2013, 81, 347-361. [CrossRef]

69. Friml, J.; Benková, E.; Blilou, I.; Wisniewska, J.; Hamann, T.; Ljung, K.; Woody, S.; Sandberg, G.; Scheres, B.; Jürgens, G.; Palme, K. AtPIN4 mediates sink-driven auxin gradients and root patterning in Arabidopsis. Cell 2002, 108, 661-673. [CrossRef]

70. Blilou, I.; Xu, J.; Wildwater, M.; Willemsen, V.; Paponov, I.; Friml, J.; Heidstra, R.; Aida, M.; Palme, K.; Scheres, B. The PIN auxin efflux facilitator network controls growth and patterning in Arabidopsis roots. Nature 2005, 433, 39. [CrossRef] [PubMed]

71. Hagen, G.; Kleinschmidt, A.; Guilfoyle, T. Auxin-regulated gene expression in intact soybean hypocotyl and excised hypocotyl sections. Planta 1984, 162, 147-153. [CrossRef] [PubMed]

72. Hagen, G.; Guilfoyle, T.J. Rapid induction of selective transcription by auxins. Plant Mol. Biol. 1985, 5, 1197-1203. [CrossRef] 
73. Yang, X.Y.; Zhang, X.L. Regulation of somatic embryogenesis in higher plants. Crit. Rev. Plant Sci. 2010, 29, 36-57. [CrossRef]

74. Gallie, D.R.; Young, T.E. The ethylene biosynthetic and perception machinery is differentially expressed during endosperm and embryo development in maize. Mol. Genet. Genom. 2004, 271, 267-281. [CrossRef] [PubMed]

75. Langhansova, L.; Konradova, H.; Vaněk, T. Polyethylene glycol and abscisic acid improve maturation and regeneration of Panax ginseng somatic embryos. Plant Cell Rep. 2004, 22, 725-730. [CrossRef]

76. Nieves, N.; Martinez, M.E.; Castillo, R.; Blanco, M.A.; González-Olmedo, J.L. Effect of abscisic acid and jasmonic acid on partial desiccation of encapsulated somatic embryos of sugarcane. Plant Cell Tissue Org. 2001, 65, 15-21. [CrossRef]

77. Von, A.S.; Hakman, I. Regulation of somatic embryo development in Picea abies by abscisic acid (ABA). J. Plant Physiol. 1988, 132, 164-169.

78. Jürgens, G. Apical-basal pattern formation in Arabidopsis embryogenesis. EMBO J. 2001, 20, 3609-3616. [CrossRef]

79. Zhu, J.K. Abiotic stress signaling and responses in plants. Cell 2016, 167, 313-324. [CrossRef] [PubMed]

80. Anil, V.S.; Rao, K.S. Calcium-mediated signaling during sandalwood somatic embryogenesis. Role for exogenous calcium as second messenger. Plant Physiol. 2000, 123, 1301-1312. [CrossRef] [PubMed]

81. Noah, A.M.; Niemenak, N.; Sunderhaus, S.; Haase, C.; Omokolo, D.N.; Winkelmann, T.; Braun, H.P. Comparative proteomic analysis of early somatic and zygotic embryogenesis in Theobroma cacao L. J. Proteom. 2013, 78, 123-133. [CrossRef] [PubMed]

82. O'Leary, B.; Park, J.; Plaxton, W.C. The remarkable diversity of plant PEPC (phosphoenolpyruvate carboxylase): Recent insights into the physiological functions and post-translational controls of non-photosynthetic PEPCs. Biochem. J. 2011, 436, 15-34. [CrossRef]

83. Aivalakis, G.; Dimou, M.; Flemetakis, E.; Plati, F.; Katinakis, P.; Drossopoulos, J.B. Immunolocalization of carbonic anhydrase and phosphoenolpyruvate carboxylase in developing seeds of Medicago sativa. Plant Physiol. Biochem. 2004, 42, 181-186. [CrossRef] [PubMed]

84. Rolletschek, H.; Borisjuk, L.; Radchuk, R.; Miranda, M.; Heim, U.; Wobus, U.; Weber, H. Seed-specific expression of a bacterial phosphoenolpyruvate carboxylase in Vicia narbonensis increases protein content and improves carbon economy. Plant Biotechnol. J. 2004, 2, 211-219. [CrossRef]

85. Jing, D.; Zhang, J.; Xia, Y.; Kong, L.; OuYang, F.; Zhang, S.; Zhang, H.; Wang, J. Proteomic analysis of stress-related proteins and metabolic pathways in Picea asperata somatic embryos during partial desiccation. Plant Biotechnol. J. 2017, 15, 27-38. [CrossRef] [PubMed]

86. Boursiac, Y.; Chen, S.; Luu, D.T.; Sorieul, M.; van den Dries, N.; Maurel, C. Early effects of salinity on water transport in Arabidopsis roots. Molecular and cellular features of aquaporin expression. Plant Physiol. 2005, 139, 790-805. [CrossRef] [PubMed]

87. Loqué, D.; Ludewig, U.; Yuan, L.; von Wirén, N. Tonoplast intrinsic proteins AtTIP2; 1 and AtTIP2; 3 facilitate NH3 transport into the vacuole. Plant Physiol. 2005, 137, 671-680. [CrossRef] [PubMed]

88. Leitão, L.; Prista, C.; Moura, T.F.; Loureiro-Dias, M.C.; Soveral, G. Grapevine aquaporins: Gating of a tonoplast intrinsic protein (TIP2; 1) by cytosolic pH. PLoS ONE 2012, 7, e33219. [CrossRef] [PubMed]

89. Murch, S.J.; Saxena, P.K. Modulation of mineral and free fatty acid profiles during thidiazuron mediated somatic embryogenesis in peanuts (Arachis hypogeae L.). J. Plant Physiol. 1997, 151, 358-361. [CrossRef]

90. Hundertmark, M.; Hincha, D.K. LEA (late embryogenesis abundant) proteins and their encoding genes in Arabidopsis thaliana. BMC Genom. 2008, 9, 118. [CrossRef] [PubMed]

91. Palovaara, J.; Hakman, I. Conifer WOX-related homeodomain transcription factors, developmental consideration and expression dynamic of WOX2 during Picea abies somatic embryogenesis. Plant Mol. Biol. 2008, 66, 533-549. [CrossRef] [PubMed]

92. Höck, J.; Meister, G. The Argonaute protein family. Genome Biol. 2008, 9, 210. [CrossRef] [PubMed]

93. Szyrajew, K.; Bielewicz, D.; Dolata, J.; Wójcik, A.M.; Nowak, K.; Szczygieł-Sommer, A.; Szweykowska-Kulinska, Z.; Jarmolowski, A.; Gaj, M.D. MicroRNAs are intensively regulated during induction of somatic embryogenesis in Arabidopsis. Front. Plant Sci. 2017, 8, 18. [CrossRef]

94. Takahata, K. Isolation of carrot Argonaute1 from subtractive somatic embryogenesis cDNA library. Biosci. Biotechnol. Biochem. 2008, 72, 900-904. [CrossRef] [PubMed] 
95. Tahir, M.; Law, D.A.; Stasolla, C. Molecular characterization of PgAGO, a novel conifer gene of the ARGONAUTE family expressed in apical cells and required for somatic embryo development in spruce. Tree Physiol. 2006, 26, 1257-1270. [CrossRef] [PubMed]

96. Munksgaard, D.; Mattsson, O.; Okkels, F.T. Somatic embryo development in carrot is associated with an increase in levels of S-adenosylmethionine, S-adenosylhomocysteine and DNA methylation. Physiol. Plant. 1995, 93, 5-10. [CrossRef]

97. Jarillo, J.A.; Piñeiro, M.; Cubas, P.; Martínez-Zapater, J.M. Chromatin remodeling in plant development. Int. J. Dev. Biol. 2009, 53, 1581-1596. [CrossRef] [PubMed]

98. Cheng, W.H.; Zhu, H.G.; Tian, W.G.; Zhu, S.H.; Xiong, X.P.; Sun, Y.Q.; Zhu, Q.H.; Sun, J. De novo transcriptome analysis reveals insights into dynamic homeostasis regulation of somatic embryogenesis in upland cotton (G. hirsutum L.). Plant Mol. Biol. 2016, 92, 279-292. [CrossRef]

99. Cao, A.; Zheng, Y.; Yu, Y.; Wang, X.; Shao, D.; Sun, J.; Cui, B. Comparative Transcriptome Analysis of SE initial dedifferentiation in cotton of different SE capability. Sci. Rep. 2017, 7, 8583. [CrossRef] [PubMed]

100. Xiao, Y.; Chen, Y.; Ding, Y.; Wu, J.; Wang, P.; Yu, Y.; Wei, X.; Wang, Y.; Zhang, C.; Li, F.; Ge, X. Effects of GhWUS from upland cotton (Gossypium hirsutum L.) on somatic embryogenesis and shoot regeneration. Plant Sci. 2018, 270, 157-165. [CrossRef] [PubMed]

101. Li, J.; Wang, M.; Li, Y.; Zhang, Q.; Lindsey, K.; Daniell, H.; Jin, S.; Zhang, X. Multi-omics analyses reveal epigenomics basis for cotton somatic embryogenesis through successive regeneration acclimation process. Plant Biotechnol. J. 2019, 17, 435-450. [CrossRef] [PubMed]

102. da Cunha Soares, T.; da Silva, C.R.C.; Chagas Carvalho, J.M.F.; Cavalcanti, J.J.V.; de Lima, L.M.; de Albuquerque Melo Filho, P.; Severino, L.S.; Dos Santos, R.C. Validating a probe from GhSERK1 gene for selection of cotton genotypes with somatic embryogenic capacity. J. Biotechnol. 2018, 270, 44-50. [CrossRef] [PubMed]

103. Xu, J.; Yang, X.; Li, B.; Chen, L.; Min, L.; Zhang, X. GhL1L1 affects cell fate specification by regulating GhPIN1-mediated auxin distribution. Plant Biotechnol. J. 2019, 17, 63-74. [CrossRef] [PubMed]

104. Wu, J.; Zhang, X.; Nie, Y.; Jin, S.X.; Liang, S.G. Factors affecting somatic embryogenesis and plant regeneration from a range of recalcitrant genotypes of Chinese cottons (Gossypium hirsutum L.). In Vitro Cell. Dev. Biol. Plant 2004, 40, 371-375. [CrossRef]

(c) 2019 by the authors. Licensee MDPI, Basel, Switzerland. This article is an open access article distributed under the terms and conditions of the Creative Commons Attribution (CC BY) license (http://creativecommons.org/licenses/by/4.0/). 